Department of Economics- FEA/USP

\title{
Price Transparency in OTC Equity Lending Markets: Evidence From a Loan Fee Benchmark
}

FÁBIo CEREdA

Fernando Chague

RoDRIGo DE-LOSSO

Alan de Genaro

BRUNo GiovanNETTI

WORKING PAPER SERIES № 2020-22 


\title{
Price Transparency in 0TC Equity Lending Markets: Evidence from a Loan Fee Benchmark
}

Fábio Cereda (fscereda@usp.br)

Fernando Chague (fernando.chague@fgv.br)

Rodrigo De-Losso (delosso@usp.br)

Alan De Genaro (alan.genaro@fgv.br)

Bruno Giovannetti (bruno.giovannetti@fgv.br)

Research Group: NEFIN

\begin{abstract}
:
We study the effects of a price transparency shock in the Brazilian OTC equity lending market. Previously, a publicly available stock-specific loan fee benchmark was the average fee of the past 15 trading days. On March 1, 2011, this interval was reduced to 3 days, significantly improving short-sellers' ability to predict current loan fees. We find that loan fees fell, lending volume increased, total lending revenue remained stable, high-cost lenders lost market share, and price efficiency increased after the benchmark change. Only a few countries benefit from loan fee benchmarks and our results may be relevant to regulators.
\end{abstract}

Keywords: price transparency, OTC markets, benchmarks, equity lending, search

JEL Codes: G12, G14, G19. 


\title{
Price transparency in OTC equity lending markets:
}

\author{
Evidence from a loan fee benchmark*
}

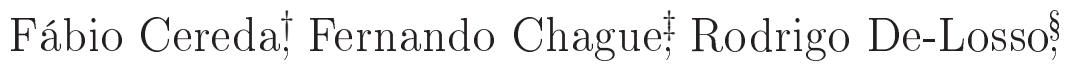 \\ Alan Genaro, Bruno Giovannetti"
}

September 12, 2020

\begin{abstract}
We study the effects of a price transparency shock in the Brazilian equity lending market, an over-the-counter market. Previously, the available loan fee benchmark was the average loan fee of the past 15 trading days. On March 1, 2011, this interval was reduced to 3 days, significantly improving short-sellers' ability to predict current loan fees. We find that after the benchmark change, loan fees fell, lending volume increased, total lending revenue remained stable, high-cost lenders lost market share, and price efficiency increased. Our results can be used by regulators considering implementing a loan fee benchmark.
\end{abstract}

JEL Codes: G12, G14, G19.

Keywords: price transparency, OTC markets, benchmarks, equity lending, search costs

${ }^{*}$ We thank Ricardo Buscariolli, Bruno Ferman, Marcelo Fernandes, Bernardo Guimarães, Bernard Herskovic, Felipe Iachan, João Manoel Pinho de Mello, Dejanir Silva, Vladimir Ponczek, and participants in seminars at Sao Paulo School of Economics-FGV and the XIII Lubrafin Meeting for their valuable comments.

${ }^{\dagger}$ Department of Economics, University of Sao Paulo, Brazil. E-mail: fscereda@usp.br

${ }^{\ddagger}$ Sao Paulo School of Economics - FGV, Brazil. Corresponding author at: Rua Itapeva, 474, Sao Paulo SP, Brazil. E-mail: fernando.chague@fgv.br.

$\S$ Department of Economics, University of Sao Paulo, Brazil. E-mail: delosso@usp.br.

`School of Business Administration - FGV, Brazil. E-mail: alan.genaro@fgv.br.

"Sao Paulo School of Economics - FGV, Brazil. E-mail: bruno.giovannetti@fgv.br. 


\section{Introduction}

Over-the-counter (OTC) markets are opaque to their participants. In the case of equity lending markets, price opacity allows lenders to act as local monopolists and charge higher loan fees from short-sellers. ${ }^{1}$ However, high loan fees are generally undesirable since they cause stock overpricing and lower stock price efficiency. ${ }^{2}$ Duffie, Dworczak, and Zhu (2017) (hereinafter, DDZ) theoretically show that benchmarks can reduce opacity and equilibrium prices, and improve welfare in OTC markets. Hence, stock markets could benefit from loan fees benchmarks. In this paper, we provide the first empirical evidence of the positive effects of a loan fee benchmark.

We explore a dataset that contains all transactions in the Brazilian equity lending market from 2008 to 2011, which is the same dataset used by Chague, De-Losso, Genaro, and Giovannetti (2017). As in other countries, the Brazilian equity lending market is OTC; however, in Brazil, all transactions are registered by the brokers at a centralized platform maintained by the Brazilian stock exchange (hereinafter, the "Exchange"). Therefore, although short-sellers face an opaque lending market, the Exchange has access to market-wide data.

On March 1, 2004, the Exchange began publicly reporting a loan fee benchmark for each stock on a daily basis in an effort to improve transparency. Initially, the benchmark was the average loan fee of the previous 15 days; on March 1, 2011, this interval was reduced to 3 days. This change was announced by the Exchange on February 23, 2011 along with the following statement: “... the purpose of this change is to make the securities lending service ever more transparent, in order to attract more securities lenders and borrowers and to meet the demand of institutional investors."

\footnotetext{
${ }^{1}$ This is shown theoretically by Duffie, Garleanu, and Pedersen (2002) and empirically by Kolasinski, Reed, and Ringgenberg (2013) and Chague, De-Losso, Genaro, and Giovannetti (2017).

${ }^{2}$ For stock overpricing see, for instance, Danielsen and Sorescu (2001), Jones and Lamont (2002), Nagel (2005), Chang, Cheng, and Yu (2007), Stambaugh, Yu, and Yuan (2012) and Blocher, Reed, and Van Wesep (2013). For price efficiency see, for instance, Asquith, Pathak, and Ritter (2005), Nagel (2005), Cao, Dhaliwal, Kolasinski, and Reed (2007), Saffi and Sigurdsson (2011), Engelberg, Reed, and Ringgenberg (2012) and Boehmer and $\mathrm{Wu}(2013)$.
} 
Reducing the interval from 15 to 3 days effectively increased the benchmark's precision and improved short-sellers' ability to predict current loan fees. As we show, the mean square error of predicting current loan fees was reduced by $35 \%$. The predictability gain from a more precise benchmark was especially important for stocks facing periods of volatile loan fees, which usually occur when shorting demand is high.

We test several predictions about the effects of the increase in price transparency. Overall, our results are consistent with the conclusion in DDZ that benchmarks can raise social surplus in OTC markets. First, we show that the new benchmark lowered prices. The stock-day average loan fee starts to fall 2.71 bps per day after the benchmark change. We also observe a similar pattern for the median, 5th percentile, and 95th percentile of the stock-day loan fees $(-2.45,-1.51$, and -4.18 bps, respectively), an indication that the entire distribution of loan fees shifted to the left after the benchmark changed. This downward shift in loan fees is also verified when we run deal-level regressions that include investor-stock fixed-effects, which suggests that the result is not solely due to a change in the composition of shortsellers - the same short-seller on the same stock was able to negotiate a lower loan fee after the benchmark change. Moreover, we find the effects to be stronger on stocks with more volatile fees, precisely the stocks that benefited the most from the improved precision of the benchmark.

Next, we show that the total volume traded increases after the benchmark change. The stock-day volume increases by approximately $1.7 \%$ per day after the change. We also find that this increase in volume occurs with a change in the composition of lenders. After the benchmark change, high-cost lenders lose market share to low-cost lenders. Moreover, the concentration of lenders also decreases, as the Herfindahl-Hirschman index computed from the fraction of deals closed by each lender on a pair stock-day falls after the benchmark change. Overall, we find that the increase in the volume is sufficiently high to compensate for the reduction in loan fees, as lenders' aggregate revenue remains stable after the benchmark change. 
Finally, we show that stock price inefficiency reduces after the benchmark change. Since the new benchmark increases the loan fee transparency, making it easier and cheaper for short-sellers to borrow stocks, our finding adds another piece of favorable evidence to the hypothesis that short-selling restrictions leads to stock price inefficiency (Bris, Goetzmann, and Zhu, 2007, Saffi and Sigurdsson, 2011, Boehmer and Wu, 2013).

Our main results are based on stock-day panel regressions using a two-month window around the benchmark change. To address concerns of a spurious relation, we run 656 panel regressions on all possible two-month window samples from July 2008 to March 2011, and find that the largest negative break in loan fees occurred precisely on March 1, 2011. In the robustness section, we also document reductions in loan fees using different windows sizes around the benchmark change. Additionally, we use a different dataset to analyze a second change in the benchmark that occurred in February 2014 but that did not significantly improve price transparency and, as expected, we find no significant effects.

We contribute to the debate among regulators and practitioners about the consequences of improving transparency in financial markets, as proposed by the 2010 Dodd-Frank Wall Street Reform and Consumer Protection Act. According to Duffie (2018), "In addition to financial-stability regulation, legislatures decided that the time is ripe for improving the competitiveness and fairness of financial markets and have asked regulators to enforce new price transparency and trade-competition requirements."

Recent papers discuss the theoretical implications of price benchmarks on OTC markets. DDZ provide a framework to discuss the implications of introducing a benchmark for price transparency in OTC markets. They conclude that benchmarks can be welfare improving and reduce the overall search costs by increasing the matching efficiency, driving high-cost dealers out of the market, and encouraging the entry of new market participants. Asriyan, Fuchs, and Green (2017) show that introducing post-trade transparency can increase welfare and trading volume, depending on the asset correlation, equilibrium being played, and the composition of market participants. Back, Liu, and Teguia (2020) also discuss the implications of post-trade 
price transparency for OTC markets. They show that investors benefit from the increase transparency because price spreads are reduced and their participation increases; dealers, in turn, may also benefit if the increase in volume offsets the smaller spreads. Aquilina and Pirrone (2020) consider a situation where a benchmark is measured with noise, and conclude that an increase in the benchmark precision increases market efficiency and market participation.

On the empirical side, most studies explore the "TRACE experiment" ${ }^{3}$ to study the introduction of a price benchmark in the U.S. corporate bonds OTC market. Bessembinder, Maxwell, and Venkataraman (2006) use transaction data from some insurance companies to study the TRACE impact and find that the new information in TRACE increased the price transparency, resulting in a large reduction of $50 \%$ in trade execution costs for bonds eligible for TRACE reporting. Goldstein, Hotchkiss, and Sirri (2006) match 90 BBB-rated actively traded corporate bonds to another 90 with similar characteristics that were not initially included in the report and find that the TRACE experiment reduced the quoted spreads. Using the complete record of all secondary trades from January 2003 to January 2005, Edwards, Harris, and Piwowar (2007) find that transaction costs fall when the TRACE system starts reporting a bond. Using an extended dataset that contains the entire corporate bond market, Asquith, Covert, and Pathak (2013) extend these findings to smaller issue size and high-yield bonds.

An exception to the use of the TRACE dataset is the work of Schultz and Song (2019), who study the introduction of post-trade transparency in the U.S. mortgage-backed securities OTC market. In November 2012, the Financial Industry Regulatory Authority began requiring dealers to report trades of mortgage-backed securities within 45 minutes-prior to that date, dealers were only required to report trades at the end of the day. The authors find that trading costs fell after the increased transparency for institutional investors, with heterogeneous effects across distinct dealers.

\footnotetext{
${ }^{3}$ The publication on July 1, 2002, by the National Association of Securities Dealers, of a report containing the most recent transactions through its trade reporting and compliance engine (TRACE).
} 
We are the first to study the effects of increased price transparency in an equity lending market. The overall positive effects of greater price transparency presented in the existing empirical literature cannot be directly extrapolated to equity lending since greater loan fee transparency could reduce the lending supply. This would be the case if the lower loan fees received by lenders were not sufficient to cover the potential losses from not selling a stock when shorting activity increases - there is a large literature that relates increases in shorting activity with lower future returns (see, for instance, Diether, Lee, and Werner, 2009, Engelberg, Reed, and Ringgenberg (2012), Rapach, Ringgenberg, and Zhou, 2016, Boehmer, Duong, and Huszar, 2018). ${ }^{4}$ Our findings, however, indicate that the increased transparency had positive effects overall; it reduced loan fees, increased lending volume, did not affect lenders' total revenue, and favored more efficient lenders.

We conclude the paper showing that only a few equity lending markets in the world have loan fee benchmarks. We collected the institutional characteristics of the most important equity lending markets around the world. Out of eighteen exchanges, only the ones in India, Singapore, and Taiwan have public information about loan fees. Moreover, in thirteen countries, the lending transactions have to be registered within their financial market infrastructure, which suggests that a loan fee benchmark could be easily implemented. Hence, our results may be relevant for regulators considering implementing a loan fee benchmark.

The remainder of the paper is organized as follows. Section 2 describes equity lending in Brazil and explains the benchmark change. Section 3 presents our main empirical analysis. Section 4 presents robustness and placebo exercises. Section 5 describes other international equity lending markets. Section 6 concludes.

\footnotetext{
${ }^{4}$ Evans, Ferreira, and Porras Prado (2017) discuss this trade-off between lending and selling stocks in the context of funds.
} 


\section{Stock lending in Brazil and the benchmark change}

The transactions in the Brazilian equity lending market occur over-the-counter, but every transaction has to be registered in the Exchange, which acts as the central counterparty. In 2011, more than US $\$ 400$ billion were lent in 1.4 million transactions. In that year, a total of 290 different stocks were traded in the lending market. In Appendix A.1 we provide further details regarding the Brazilian equity lending market.

The first equity lending transactions in Brazil occurred in the 1970's. At that time, deals between borrowers and lenders were closed without any regulation. In 1996, the Exchange began to act as the central counterparty in this market, but loan deals continued to occur over-the-counter with low transparency to market participants.

To improve the market transparency, on March 1, 2004, the Exchange started to report a daily stock-level loan fee benchmark. The benchmark consisted of a moving average of the "daily average loan fee" over the previous 15 days. More precisely, the benchmark for stock $s$ available for short-sellers on day $t$ was the average of $\overline{F e e}_{s, t-1}, \overline{F e e}_{s, t-2}, \ldots$, and $\overline{F e e}_{s, t-15}$, where $\overline{F e e}_{s, t-j}$ is the volume-weighted average loan fee paid by short-sellers across all loan deals of stock $s$ initiated on day $t-j$.

On March 1, 2011, the interval used to compute the benchmark was reduced from 15 to 3 trading days. That is, the benchmark for stock $s$ available for short-sellers on day $t$ was modified to be the average of $\overline{F e e}_{s, t-1}, \overline{F e e}_{s, t-2}$, and $\overline{F e e}_{s, t-3}$. On February 23, 2011, the Exchange released a statement announcing this change and explaining its reasons. According to the Exchange (see Appendix A.2), “... the purpose of this change is to make the securities lending service ever more transparent, in order to attract more securities lenders and borrowers and to meet the demand of institutional investors".

Since our full dataset begins in 2008, we cannot study the effects of the introduction of the benchmark in 2004. We focus our analysis on the benchmark change that occurred in 2011. As we show, the simple change in the moving-average window from 15 to 3 days was sufficient to significantly increase loan fee transparency and affect a number of relevant 
variables in the equity lending market.

\section{$2.1 \quad$ Dataset}

Our dataset contains all the loan transactions closed on the 55 most liquid stocks in the Brazilian stock market from July 2008 to July 2011, along with information about the number of shares, the loan fee, and unique identifications (anonymous, but fixed over time) for borrowers and lenders. This dataset was also used by Chague, De-Losso, Genaro, and Giovannetti (2017) to show that short-sellers who are well connected in the equity lending market pay lower loan fees.

To keep market conditions relatively stable, we focus our main analyses on a two-month window around the benchmark change, i.e., February and March 2011. Both months presented positive market returns with relatively low volatility - the cumulative market return was $1.21 \%$ in February and $1.78 \%$ in March; the annualized volatility of daily market returns was $19.6 \%$ and $15.8 \%$ in February and March, respectively.

Among the 55 stocks used in Chague, De-Losso, Genaro, and Giovannetti (2017), we select the 30 stocks for which there was no payment of dividends of the type "interests on equity" between February and March 2011. The reason is that these dividend payments temporarily distort loan fees, as follows. According to a Brazilian law (which was amended in August 2014), the tax treatment of "interest on equity" was different for different investors: individual investors and foreign financial institutions had to pay a tax rate of $15 \%$; in turn, national financial institutions were exempt. As a result, on days around the ex-date of interest on equity, a tax arbitrage trade between taxable and non-taxable investors occurred as follows: (i) taxable investors lent shares to non-taxable investors at a higher loan fee; (ii) non-taxable investors received the interest on equity, paying no taxes; (iii) non-taxable investors transferred to taxable investors the net value (i.e., excluding taxes) that taxable investors would receive from interest on equity; and (iv) taxable investors then received a higher loan fee, while non-taxable investors profited by $15 \%$ of the interest on equity minus 
the loan fee. Since the loan fees from these arbitrage deals are artificially high (see Barbosa, Bonomo, De Mello, and Mota, 2018), we exclude the stocks that had such an event in February and March 2011.

Our final sample consists of all 51,411 loan deals closed for 30 liquid stocks between February and March 2011. Table 1 presents some descriptive statistics for these stocks. The two stocks with the lowest market capitalization in our sample were worth US\$ 1.9 billion at the end of January 2011 (BTOW3, the online retail company B2W, and GOLL4, the low-cost airline company Gol). The largest one was worth US\$36.2 billion (AMBV4, the brewing company Ambev). The total volume shorted in these two months for these 30 stocks was US\$ 8.9 billion.

In columns 3 and 4 of Table 1, we show the average daily lending volume (in US\$ million) before (February 2011) and after (March 2011) the benchmark change, respectively, for each stock. In column 5, we present for each stock the percentage change between these two volumes. Analogously, in columns 6 and 7, we show the average loan fee (per year, in basis points) before and after the benchmark change, respectively, for each stock. In column 8, we show the difference between these two average loan fees. The t-statistics computed using column 5 (2.17) and column 8 (-1.99), present an initial statistical evidence of the effects of the benchmark change; it has possibly increased lending volume and decreased loan fees. In Section 3 we study these effects in more detail.

[Table 1 about here]

\subsection{The new benchmark increased price transparency}

Short-selling is, in general, a short-horizon investment strategy (according to Chague, DeLosso, and Giovannetti, 2019, the median duration of a shorting deal in Brazil is 12 trading 
days) and loan fees can change fast. Hence, reducing the moving-average window of the benchmark from 15 to 3 days increases the ability of short-sellers to predict the current loan fees, especially for stocks facing rapid swings in loan fees.

To assess the differences among the two benchmarks (the old 15- and the new 3-day moving average), we reconstruct them using our dataset and compare both with the actual daily average loan fee. Importantly, we note that directly using the benchmark to predict the current loan fees was possibly the only prediction model available for short-sellers; since they did not observe the historical daily average loan fee, they were not able to run regressions of this variable on the benchmark to estimate more elaborated prediction models.

As a first visual analysis, we focus on two different stocks over the six-month period prior to the implementation of the new benchmark. We compute the error incurred when using both benchmarks to predict the actual daily average loan fee and accumulate the absolute errors over time. As figure 1 shows, the 3 -day benchmark provides a more accurate prediction of the current loan fee in periods when the loan fee is more volatile.

[Figure 1 about here]

We next measure the informational gain produced by the benchmark change using the complete dataset (the same 30 stocks from July 2008 to July 2011). As before, we use both benchmarks for stock $s$ available on day $t$ as predictors of the value- and equal-weighted average loan fee of stock $s$ on day $t$. We then compute both the mean square error (MSE) and the mean absolute error (MAE) under the 15- and the 3-day benchmarks. Considering the daily value-weighted average loan fee as the predicted variable, the MSE under the 3-day benchmark is $65 \%$ of the one under the 15-day benchmark, and the MAE under the 3-day benchmark is $84 \%$ of the one under the 15-day benchmark. When considering the daily equal-weighted average loan fee as the predicted variable, these numbers are $66 \%$ and $89 \%$, respectively. 
If we focus on the two months around the benchmark change (February and March 2011), the differences are even higher. When considering the daily value-weighted average loan fee as the predicted variable, the MSE under the 3-day benchmark is $59 \%$ of the one under the 15-day benchmark, and the MAE under the 3-day benchmark is $72 \%$ of the one under the 15-day benchmark. When considering the daily equal-weighted average loan fee as the predicted variable, these numbers are $57 \%$ and $77 \%$, respectively. That is, overall, the benchmark change improved the ability of short-sellers to predict the current loan fees.

\section{The effects of the benchmark change}

DDZ develop a theoretical framework to study the effects of price benchmarks on OTC markets. In their model, traders (short-sellers, in our case) sequentially search over a finite number of dealers (lenders, in our case) to find a good deal. At each point, the trader has to decide whether to accept the price offered, obtain a different quote at another dealer, or exit the market. There is heterogeneity across traders; slow traders face higher search costs and may even decide not to enter the market. Dealers are also heterogeneous in the costs they face. Each dealer's total cost is the sum of a common component cost and a dealer-specific component. Because searching for, or delaying closing a deal, is costly, the dealers can exploit local monopoly powers and charge higher prices from traders.

In DDZ's model, the price benchmark reveals to all traders the dealers' common component cost. Therefore, when available, the benchmark informs traders that the offered price is relatively high and that it might be worthwhile to continue to search. The benchmark also prevents wasteful searching by informing traders that the price they found is good enough.

DDZ's overall conclusion is that benchmarks are usually welfare improving. ${ }^{5}$ This is the

\footnotetext{
${ }^{5}$ They also discuss a specific case where publishing benchmarks can lower welfare by discouraging lenders, who exit the market. According to DDZ's model, this could happen when markets are already relatively efficient without the benchmark, i.e., in markets with relatively low search costs. This is unlikely the case for the equity lending market, as a large fraction of short-sellers face large search costs (see Chague, De-Losso, Genaro, and Giovannetti, 2017). Indeed, as we show below, lending volume actually increases, and loan fee decreases, after the benchmark change.
} 
result of a combination of the following three effects: i) the gains from trade produced by the increase in the overall trading activity, as the competition among dealers produce lower prices and encourage the participation of traders; ii) the improved matching efficiency, as inefficient dealers with high idiosyncratic costs are driven out of the market; and iii) the reduction in wasteful searching, which follows from the reduction in the information asymmetry.

The theoretical implications in DDZ for OTC markets naturally extend to the equity lending market. The equity lending market is an OTC market which has been characterized as a market where short-sellers have to search for security lenders to borrow shares (see, for instance, Duffie, Garleanu, and Pedersen, 2002, for a dynamic model of the securities market). Additionally, short-sellers face non-negligible search costs in the equity lending market, which can be particularly high for some stocks and for poorly connected investors (see Chague, De-Losso, Genaro, and Giovannetti, 2017). Moreover, costly delays are certainly a concern since short-sales are short-lived deals that rely on superior market timing and fast information processing (see, for instance, Diether, Lee, and Werner, 2009, Engelberg, Reed, and Ringgenberg, 2012, and Chague, De-Losso, and Giovannetti, 2019). Finally, there is heterogeneity across lenders (see Prado, Saffi, and Sturgess, 2016); while some investors are occasional lenders (e.g., hedge funds and retail investors), others have large holdings, rarely trade, and often lend their stocks (e.g., large pension funds, index funds, or even large company insiders who have to hold the stock).

We test five hypotheses related to the benchmark change. The first two hypotheses rely on the theoretical prediction that benchmarks can raise welfare by lowering prices and encouraging more trade. Based on Theorem 1 in DDZ, ${ }^{6}$ this should occur whenever shortsellers face non-negligible search costs and lenders' costs are not too high—both conditions are typically observed on equity lending markets (see Chague, De-Losso, Genaro, and Giovannetti, 2017, for evidence of search costs, and Duffie, Garleanu, and Pedersen, 2002, for an argument of lenders' low costs). Accordingly, the first two hypotheses are the following:

\footnotetext{
${ }^{6}$ Figures 2 and 3 in DDZ illustrate the direction of the modeled effects. Back, Liu, and Teguia (2020) also show that post-trade price transparency can produce lower spreads and higher volume.
} 
Hypothesis 1: Loan fees fall with the new benchmark.

Hypothesis 2: The lending volume increases with the new benchmark.

Our third hypothesis follows from the reduction in the information asymmetry produced by the benchmark change. According to Proposition 8 in DDZ, we expect that better informed short-sellers will search for lower loan fees, benefiting more the efficient lenders (see also Aquilina and Pirrone, 2020). As such, the third hypothesis is the following:

Hypothesis 3: High-cost lenders lose market share with the new benchmark.

DDZ and Back, Liu, and Teguia (2020) discuss instances where the increase in trading volume can be sufficiently high to offset the reduction in prices and maintain, or even increase, the total revenue of dealers. Indeed, in some cases dealers themselves can decide to introduce benchmarks. ${ }^{7}$ Hence, our fourth hypothesis is the following:

Hypothesis 4: The lenders' aggregate revenue is not reduced with the new benchmark.

Finally, our fifth hypothesis is based on a large number of studies showing that limits to short-selling result in stock price inefficiency. Bris, Goetzmann, and Zhu (2007) study the institutional details of 46 equity markets around the world and find that those markets where short-selling is facilitated tend to have stock prices that respond faster to negative information. Using data on lending supply postings over 26 countries, Saffi and Sigurdsson (2011) show that stocks that have a low lending supply and, therefore, are costly to borrow, tend to have lower price efficiency. Using data from NYSE stocks from the Regulation SHO pilot program, Boehmer and Wu (2013) show that stock prices are more efficient when short-sellers trade mode actively. Therefore, if the benchmark change increases the price transparency, making it cheaper for short-sellers to borrow stocks, we should also observe an improvement in the stock price efficiency. The fifth hypothesis is then the following:

\footnotetext{
${ }^{7} \mathrm{DDZ}$ pose the following question. "Who implements a benchmark? Perhaps surprisingly, dealers often have sufficiently strong incentives to add a benchmark. What matters is whether the resulting reduction in dealer profit margin is more than offset by the increased volume of trade."
} 
Hypothesis 5: The stock price efficiency increases with the benchmark change.

We now test these five hypotheses, one per section.

\subsection{Hypothesis 1: Effect on loan fees}

In this section, we test if loan fees fall with the introduction of the new benchmark. As a first examination, we plot the time-series of $\overline{F e e}_{t}$, the average loan fee on day $t$ across all stocks. To compute $\overline{F e e}_{t}$ we first calculate $\overline{F e e}_{s, t}$, the average loan fee across all loan deals for each stock $s$ on day $t$, and then compute the average of $\overline{F e}_{s, t}$ across all stocks. Figure 2 presents the evolution of $\overline{F e e}_{t}$ around the benchmark change, during February and March of 2011, with day zero being March 1, 2011 ( $\overline{F e}_{t}$ is annualized and in percentage points).

[Figure 2 about here]

Figure 2 shows that the average loan fee across all stocks was trending upwards in February 2011, reaching $2.75 \%$ per year just before the benchmark change. Then, coinciding with the benchmark change, we see a break in the time-trend of the series, where the average loan fee starts to fall over the following weeks. Hence, the visual analysis of the data suggests that the new benchmark possibly had a gradual effect on loan fees, i.e., a break in the time-trend rather than a discontinuous shift. A potential reason could be that the number of short-sellers aware of the benchmark change gradually increased after the change.

We first formally test the existence of a break in the time-trend of loan fees, as indicated by figure 2. To do so, we run the following stock-day level panel regressions:

$$
\phi_{s, t}=\beta_{0}+\beta_{1} t+\beta_{2} t \times \text { After }_{t}+\boldsymbol{\beta}_{\mathbf{3}}^{\prime} \boldsymbol{X}_{\boldsymbol{s , t}}+\alpha_{s}+\varepsilon_{s, t}
$$

where $\phi_{s, t}$ represents different stock-day statistics for the loan fee (average, median, 5th and 95th percentiles of the loan fees in each stock-day, in basis-points) computed using all loan 
deals of stock $s$ on day $t ; t$ is a linear time-trend; After ${ }_{t}$ is a dummy variable that equals one from March 1, 2011 onwards; $\alpha_{s}$ are stock fixed effects; and $\boldsymbol{X}_{s, t}$ are three control variables related to stock $s$ on day $t$, namely, the stock returns over the last 5 and 240 trading days (to capture short-run price reversion and long-run price momentum) and the standard deviation of the daily stock returns over the last 10 trading days.

The specification of equation 1 is straightforward. The goal is to test whether the timetrend of loan fees bends downwards with the introduction of the new benchmark, as suggested by figure 2, controlling for stock fixed-effects and some stock-specific time varying variables. If there occurred a negative break in the time-trend of loan fees, $\beta_{2}$ should be negative. Columns 1, 2, and 3 of Table 2 present the estimates of equation 1 using the average stockday loan fee as the dependent variable. Column 1 includes only the trend and its interaction with After $_{t}$ as regressors, column 2 adds stock fixed-effects, and column 3 adds the additional controls. The estimates across all specifications show a significant break in the loan fee timetrend after the benchmark change. Considering the estimates in column 1, each additional day after the new benchmark reduces the average loan fee by 2.71 bps, or $1.09 \%$, taking the constant as a reference $(0.0109=2.71 / 249.11)$ — the constant equals the average loan fee at the beginning of February.

\section{[Table 2 about here]}

Columns 4, 5, and 6 of Table 2 show the same regressions but with the median loan fee as the dependent variable - for each stock-day we compute the median loan fee across all loan deals. As the estimates of $\beta_{2}$ show, the change in the benchmark also affected the time-trend of the median loan fee. Considering the estimates in column 4, each additional day after the new benchmark reduces the median loan fee by $2.54 \mathrm{bps}$, or $1.04 \%$ taking the constant as a reference $(0.0104=2.54 / 244.93)$.

Table 3 shows the estimates of equation 1 when we use the 5 th and the 95 th percentiles 
of the loan fees across all loan deals closed in each stock-day as the dependent variables. Considering the estimates in column 1, each additional day with the new benchmark reduces the 5 th percentile loan fee by 1.51 bps, or $1.06 \%$ with respect to the 5 th-percentile fee at the beginning of February $(0.0106=1.51 / 142.29)$. Considering the estimates in column 4 , each additional day with the new benchmark reduces the 95th percentile loan fee by 4.18 bps, or $1.08 \%$ with respect to the average 95 th percentile fee at the beginning of February $(0.0108=4.18 / 386.6)$.

[Tables 3 about here]

Tables 2 and 3 suggest that the benchmark affected the dynamics of the entire distribution of loan fees (average, median, left, and right tales). The entire distribution starts shifting to the left in March 2011.

\subsubsection{The March 2011 time-trend break in perspective}

One immediate concern is that the time-trend break observed at the beginning of March 2011 is unrelated to the benchmark change and that such breaks actually occur frequently. We next address this reasonable concern by running the same stock-day panel regression in column 3 of Table 2 for every possible 40-day window from the beginning of the sample (July 2008) to the true benchmark change (March 2011).

Around each trading day within this period (starting from August 1st, 2008), we open a

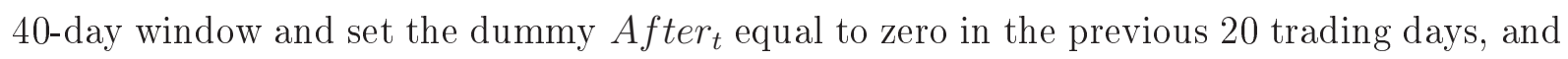
to one in the following 20 trading days. Figure 3 shows the t-statistics of the coefficient $\beta_{2}$ obtained from the resulting 656 different panel regressions, sorted by their magnitude from lowest to highest. As we can see, the t-statistics obtained from the regressions that have

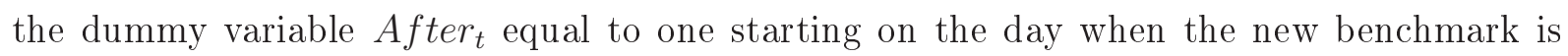


published (March 1, 2011), and also on the previous day (February 28, 2011), stand out as the largest and most negative t-statistics. From this, we conclude that the time-trend break in loan fees that occurred coinciding with the benchmark change was indeed atypical.

[Figure 3 about here]

\subsubsection{The time-trend break with investor-stock fixed effects}

Chague, De-Losso, Genaro, and Giovannetti (2017) show that some short-sellers are able to negotiate better loan fees than other short-sellers. Therefore, it could be that the loan fee time-trend simply changes in March 2011 due to a possible coinciding change in the composition of short-sellers. We next account for this possibility by using the investor-level granularity of our dataset to run the following deal-level panel regression

$$
F e e_{i, s, t, k}=\beta_{0}+\beta_{1} t+\beta_{2} t \times \text { After }_{t}+\boldsymbol{\beta}_{\mathbf{3}}^{\prime} \boldsymbol{X}_{\boldsymbol{s}, t}+\alpha_{s, k}+\varepsilon_{i, s, t, k}
$$

where $F e e_{i, s, t, k}$ is the loan fee in bps for deal $i$ of stock $s$ closed on day $t$ by short-seller $k$, After $_{t}$ is a dummy variable that equals one from March 1, 2011 onward, $t$ is a linear timetrend, $X_{s, t}$ are the same control variables related to stock $s$ on day $t$ used in the previous section, and $\alpha_{s, k}$ are investor-stock fixed effects (that is, one dummy variable for each pair of investor $k$ and stock $s$ ).

[Table 4 about here]

Because of the presence of investor-stock fixed effects in this regression, $\beta_{2}$ is estimated within each investor-stock pair, being not affected by possible changes in the composition of short-sellers. Table 4 presents the estimates. Our main results are in columns 3 and 4, 
where we include stock-investor fixed effects, but we also show the results using no fixed effects (column 1) and stock fixed effects (column 2). The estimates of $\beta_{2}$ remain negative and significant; they imply that the same investor when shorting the same stock paid lower loan fees after the benchmark change. The economic magnitude of the effect is similar to that observed before. According to the result in column 1, each additional day with the new benchmark reduces the loan fee by 2.64 bps.

Because the observations in regression 2 are at the deal level, stocks with more loan deals will have a greater effect on the estimates. This could be a problem if a small set of stocks accounted for a very large fraction of deals and the results were concentrated on these stocks. To adjust for that, columns $5,6,7$, and 8 show weighted regressions that ensure that each stock has the same weight. The results remain qualitatively the same.

\subsubsection{Heterogeneous effects across stocks}

As discussed in Section 2.2, the more volatile the loan fee, the greater the informational gain when moving from the 15- to the 3-day benchmark. We should then expect the benchmark change to have produced stronger effects on the stocks that were facing more volatile loan fees at the specific moment of the benchmark change.

To evaluate this, we split the 30 stocks into two groups of 15 stocks each, according to the volatility of their loan fees during the 10-day period just before the benchmark change. We split the stocks as follows. We first compute the average loan fee of each stock on each day $\left(\overline{F e e}_{s, t}\right)$ and then compute for each stock the standard deviation of $\overline{F e e}_{s, t}$ during the 10-day period just before the benchmark change. We rank the stocks according to these standard deviations and split them into two groups: high and low loan fee volatility. Figure 4 presents the loan fee volatility of each stock in the 10-day period just before the benchmark change.

[Figure 4 about here] 
As a first visual analysis, as in Section 3.1, we plot the time-series of the daily average loan fee across the 15 stocks in the low-volatility group and the time-series of the daily average loan fee across the 15 stocks in the high-volatility group (annualized and in percentage points). Figure 5 presents both series. It shows that the effect of the new benchmark is stronger for the stocks in the high-volatility group. For these stocks, the average loan fee was trending upwards in February 2011 and, in March 2011, it begins to trend downwards. For the stocks in the low-volatility group, the break in the time-trend is less clear.

[Figure 5 about here]

To formally test the difference in the time-trend break between the two groups, we estimate the same stock-day panel regressions presented in equation 1, but we now allow for different time-trend breaks for the stocks in the low- and high-volatility groups, as follows:

$$
\begin{aligned}
\phi_{s, t} & =\beta_{0}+\beta_{1} t+\beta_{2} t \times \text { After }_{t} \\
& +\beta_{3} H_{i g h_{s}}+\beta_{4} t \times H i g h_{s}+\beta_{5} t \times \text { After }_{t} \times H i g h_{s}+\boldsymbol{\beta}_{\mathbf{6}}^{\prime} \boldsymbol{X}_{s, t}+\alpha_{s}+\varepsilon_{s, t}
\end{aligned}
$$

where $H i g h_{s}$ is a dummy equal to one for the stocks in the high-volatility group and zero otherwise. As before, $\phi_{s, t}$ represents different loan fee statistics (average, median, 5th and 95th percentiles of the loan fees in basis points) computed using all the loan deals of stock $s$ on day $t, t$ is a linear time-trend, After ${ }_{t}$ is a dummy variable that equals one from March 1, 2011 onwards, $\alpha_{s}$ are stock fixed effects, and $\boldsymbol{X}_{s, t}$ are the same control variables related to stock $s$ on day $t$.

Table 5 shows the results. The coefficient of interest is now $\beta_{5}$; it should be negative in case the time-trend break after the benchmark change is stronger for the stocks in the high-volatility group. Consistent with figure 5, this is what we find. Column 3 considers 
the average loan fee for each stock-day as the dependent variable and employs the full set of controls. According to column 3, there was no significant break in the time-trend for the stocks in the low-volatility group $\left(\beta_{2}=0.18\right.$, t-statistic of 0.23$)$ but there was a significant break in the time-trend for the stocks in the high-volatility group ( $\beta_{5}=-4.64$, t-statistic of -2.44). The results are analogous for the other loan fee statistics. For the median, the 5 th percentile, and the 95 th percentile, $\beta_{5}$ is always negative and significant, indicating a stronger time-trend break for the stocks in the high-volatility group.

[Tables 5 about here]

\subsection{Hypothesis 2: Effect on the lending volume}

In this section, we test whether the lending volume increased with the new benchmark. We first compute $V_{s, t}$, the total volume lent for stock $s$ on day $t$ (in thousands of US\$), and use it as the dependent variable in our baseline stock-day panel regression, as follows:

$$
V_{s, t}=\beta_{0}+\beta_{1} t+\beta_{2} t \times \text { After }_{t}+\boldsymbol{\beta}_{\mathbf{3}}^{\prime} \boldsymbol{X}_{\boldsymbol{s}, t}+\alpha_{s}+\varepsilon_{s, t}
$$

where, as before, After ${ }_{t}$ is a dummy variable that equals one from March 1, 2011 onward, $t$ is a linear time trend, $X_{s, t}$ are control variables, and $\alpha_{s}$ are stock fixed effects.

Columns 1, 2, and 3 of Table 6 present the results. The estimated coefficients indicate an increase in the lending volume after the benchmark is introduced. Considering column 1, each day with the new benchmark increases the total volume lent by US\$130.95 thousands, an increase of $1.42 \%$ per day with respect to the total volume lent at the beginning of the sample $(0.0142=130.95 / 9,250)$. The change remains statistically significant when we include stocks fixed effects in column 2 and the controls in column 3.

[Table 6 about here] 
In columns 4,5 , and 6 of Table 6 we replace the dependent variable with $\ln V_{s, t}$, the natural $\log$ of $V_{s, t}$. The conclusions are qualitatively the same. Considering the estimate of $\beta_{2}$ in column 4 , the total volume lent per stock-day increases by approximately $1.7 \%$ per day after the benchmark is introduced. The numbers remain the same when we include stock fixed effects in column 5, and increases slightly to $1.9 \%$ in column 6 when the other controls are also included.

\subsection{Hypothesis 3: Effect on lenders' market share}

We now assess how the benchmark change affected the composition of lenders in the equity lending market. In particular, we are interested in the hypothesis that high-cost lenders lose market share to low-cost lenders, given that better informed short-sellers would search for lenders who charge lower fees.

We run our baseline stock-day panel regression again, as follows:

$$
Y_{s, t}=\beta_{0}+\beta_{1} t+\beta_{2} t \times \text { After }_{t}+\boldsymbol{\beta}_{\mathbf{3}}^{\prime} \boldsymbol{X}_{s, t}+\alpha_{s}+\varepsilon_{s, t}
$$

where the dependent variable, $Y_{s, t}$, now can be one of the following three lender-related variables: i) the log of the number of different lenders (those responsible for at least one loan deal) for stock $s$ on day $t$; ii) the Herfindahl-Hirschman index (HHI) computed from the fraction of deals closed by each lender on stock $s$ on day $t$; and iii) the market share (in $\%)$ of high-cost lenders for stock $s$ on day $t$.

We compute the market share of high-cost lenders of stock $s$ on day $t$ as follows. We first classify all lenders with at least one loan deal in February 2011 as "low-cost" or "highcost". A lender is classified as high-cost if he charged an "expensive" loan fee in more than $50 \%$ of the loan deals closed by him in February 2011 (the loan fee of a deal is defined as expensive if it is higher than the average loan fee for that specific stock on that specific day); otherwise, the lender is classified as low-cost. We then compute the fraction of deals closed 
by all high-cost lenders for each stock-day in February and March 2011 .

Table 7 shows the results. In columns 1 to 3 , the number of different lenders is the dependent variable. The point estimates for $\beta_{2}$ are always positive, but are not statistically significant, except for the estimate in column 3. That is, there is no evidence of a change in the number of different lenders. However, according to columns 4 to 6 , the new benchmark contributed to a lower concentration in the lending activity; there is a negative break in the time-trend of the Herfindahl-Hirschman index. Finally, columns 7 to 9 show that high-cost lenders (the ones who charged relatively high loan fees before the benchmark change) lost market share with the new benchmark. The constant of column 7 indicates that high-cost lenders had a market share of $70.76 \%$ at the beginning of February 2011. In turn, the estimate of $\beta_{2}$ indicates that this share begins to reduce $0.21 \%$ per day with the introduction of the new benchmark.

[Table 7 about here]

\subsection{Hypothesis 4: Effect on the lenders' aggregate revenue}

A benchmark can increase the traded volume to the point that the dealers' total revenue does not decrease (or even increases), despite having their prices reduced. Indeed, as discussed by DDZ, in some over-the-counter markets, dealers have the incentive to publish price benchmarks themselves. This is the case, for instance, of the LIBOR, the widely-used benchmark for short-term interest rates published by the major financial institutions.

On the one hand, in Section 3.1, we show that the loan fees decreased with the new benchmark. On the other hand, in Section 3.2, we show that the lending volume increased. Was the increase in the lending volume sufficiently high to compensate lenders for the reduction in the loan fees? To answer this question, we run our same baseline stock-day regression 
using lending revenue as the dependent variable, as follows:

$$
L R_{s, t}=\beta_{0}+\beta_{1} t+\beta_{2} t \times A f t e r_{t}+\boldsymbol{\beta}_{\mathbf{3}}^{\prime} \boldsymbol{X}_{\boldsymbol{s}, t}+\alpha_{s}+\varepsilon_{s, t}
$$

where $L R_{s, t}$, is the total lending revenue (loan fee times loan volume, in thousands of US\$) across all loan deals of stock $s$ on day $t$ and, as before, After ${ }_{t}$ is a dummy variable that equals one from March 1, 2011 onward, $t$ is a linear time trend, $X_{s, t}$ are control variables, and $\alpha_{s}$ are stock fixed effects. The results are reported in Table 8. The point estimates for $\beta_{2}$ are always positive but not statistically significant, except for column 6 . We hence conclude that the benchmark change did not significantly altered the lenders' aggregate revenue, that is, the increase in the lending volume was sufficiently high to compensate lenders for the reduction in the loan fees.

[Table 8 about here]

\subsection{Hypothesis 5: Effect on the stock price efficiency}

In this section, we test whether the stock price efficiency increased after the introduction of the new benchmark. Different papers measure price efficiency in slightly different ways. ${ }^{8}$ A common measure is the one proposed by Hou and Moskowitz (2005). This measure uses stock-week regressions to extract stock-specific measures of price delays to market shocks. The literature seems to agree that the weekly frequency, rather than monthly or daily frequencies, provides an appropriate compromise between a minimum number of observations and reduced noise due to micro-structure and non-synchronous trading. Specifically, the

\footnotetext{
${ }^{8}$ Hou and Moskowitz (2005) (HM) use i) weekly regressions of stock returns on market returns and their lags to obtain price delay measures. Bris, Goetzmann, and Zhu (2007) (BGZ) use i) HM's weekly regression based measures and ii) cross-autocorrelations of stock returns and lagged market returns. Saffi and Sigurdsson (2011) use i) HM's weekly regression based measures, ii) BGZ' cross-autocorrelations, and iii) variance ratios of stock returns sampled with different frequencies to capture deviations from a random walk hypothesis. Finally, Boehmer and Wu, 2013 use i) HM's weekly regressions, ii) stock autocorrelations using high-frequency data, iii) a pricing error measure obtained by decomposing observed (log) transaction price, pt, into an efficient price (random walk) component, $\mathrm{mt}$, and a stationary component
} 
usual regression is as follows:

$$
R_{s, w}=\beta_{0}+\beta_{1} R_{m, w}+\sum_{i=1}^{4} \delta_{i} R_{m, w-i}+\epsilon_{s, w}
$$

where $R_{s, w}$ is the stock return for stock $s$ in week $w$ and $R_{m, w}$ is the market return in week $w$.

The first measure of price inefficiency is as follows:

$$
D 1=1-R_{R}^{2} / R_{U}^{2}
$$

where $R_{U}^{2}$ is the $\mathrm{R}$-squared from the regression 3 (unrestricted regression), and $R_{R}^{2}$ is the R-squared from the regression above restricting $\delta_{1}, \delta_{2}, \delta_{3}$, and $\delta_{4}$ to be zero (restricted regression).

The second measure of price inefficiency compares the importance of lagged market returns relative to the contemporaneous market returns by examining the value of the estimated coefficients, accounting for their statistical significance. It is as follows:

$$
D 2=\sum_{i=1}^{4} t\left(\delta_{i}\right) /\left[t\left(\beta_{1}\right)+\sum_{i=1}^{4} t\left(\delta_{i}\right)\right]
$$

where $t()$ denotes the t-statistic of the coefficient.

Because short-selling specifically facilitates the incorporation of negative news, we also compute two other measures based on the following regression:

$$
R_{s, w}=\beta_{0}+\beta_{1} R_{m, w}^{-}+\sum_{i=1}^{4} \delta_{i} R_{m, w-i}^{-}+\epsilon_{s, w}
$$

where $R_{m, w}^{-}$equals the market return when it is negative and zero otherwise.

Based on regression 4, we compute two other measures of price inefficiency. The first one is as follows: 


$$
D 3=1-\widetilde{R}_{R}^{2} / \widetilde{R}_{U}^{2}
$$

where $\widetilde{R}_{U}$ is the R-squared from the regression 4 , and $\widetilde{R}_{U}$ is the R-squared from a regression that excludes lags. The second one is as follows:

$$
D 4=\sum_{i=1}^{4} t\left(\delta_{i}^{-}\right) /\left[t\left(\beta_{1}^{-}\right)+\sum_{i=1}^{4} t\left(\delta_{i}^{-}\right)\right]
$$

where, as before, $t()$ denotes the t-statistic of the coefficient in parenthesis.

For each stock, we compute a price inefficiency measure before and after the benchmark change using three different sample windows of 3,6, and 12 months. Table 9 shows that in all cases we observe a reduction in the price inefficiency. To determine if the changes are statistically significant, we follow Bris, Goetzmann, and Zhu (2007) and use the nonparametric Kruskal-Wallis test. At the 5\% significance level, the changes in all four measures are negative and statistically significant at the 6- and 12-month windows.

[Table 9 about here]

\section{Further analyses}

In this section we run three additional exercises to complement the evidence presented in the previous section. First, we present an alternative specification for our main table (Table 2); we use day fixed-effects instead of the linear time-trend with break. Second, we employ wider time windows around the 2011 benchmark change. Third, we analyze the effects on the loan fees of a second benchmark change that occurred in 2014.

\subsection{Day fixed-effects}

Our baseline analysis tests whether there occurred a break in the time-trend of loan fees coinciding with the date of the benchmark change. The specification of equation 1 test this 
hypothesis. A more flexible specification could, in turn, employ day fixed-effects instead of the linear trend with break, including on the right-hand side of the regression a different constant for each day, and excluding variables $t$ and $t \times A f t e r_{t}$. We now replicate Table 2 using this more flexible specification. Table 10 presents the results.

\section{[Table 10 about here]}

The constant term in all columns of Table 10 refers to the day of the benchmark change, March 1, 2011 (once we omit the day fixed-effect for this specific date). Hence, each one of the estimated day fixed-effects compares the loan fees on that respective day with the loan fees on March 1, 2011. Columns 1 and 2 present the regressions that use the average stock-day loan fee as the dependent variable. Column 1 has only the day fixed-effects as the explanatory variables and column 2 adds stock fixed-effects and the additional controls. In both columns we find that the fixed-effects for the dates before the benchmark change are not significant. That is, the average loan fees on these dates are not significantly different from the average loan fee on March 1, 2011. In turn, most of the fixed-effects for the dates after the benchmark change are negative and significant, indicating a reduction in loan fees after the benchmark change. Columns 3 and 4 present the regressions that use the median stock-day loan fee as the dependent variable. Results are qualitatively the same.

\subsection{Other intervals}

To ensure a proper identification of the effects from the benchmark change and avoid confounding effects, we need the market conditions in the period after the change to be as similar as possible to the conditions before the change. Because of that, we use a relatively small 2-month window around the change (one month before, one month after). Both months presented positive market returns with relatively low volatility - the cumulative market return was $1.21 \%$ in February and $1.78 \%$ in March; the annualized volatility of the daily market returns was $19.6 \%$ and $15.8 \%$ in both months, respectively. 
We now replicate our main regression (equation 1) using wider windows around the benchmark change as follows: (i) two months before (January and February 2011) and two months after (March and April 2011) and (ii) four months before (November 2010 to February 2011) and four months after (March to June 2011). Overall, the results also show a significant negative break for the time-trend of loan fees by the occasion of the benchmark change, although with less precision.

Table 11 presents the results. Columns 1, 2, 3, and 4 are estimated using all loan deals from January to April 2011. According to column (1), where the dependent variable is the average loan fee for each stock-day, the time-trend break is significant at the $10 \%$ level. Columns 5, 6, 7, and 8 are estimated using all loan deals from November 2010 to June 2011. According to column 5, where the dependent variable is the average loan fee for each stock-day, the time-trend break is also significant at the $10 \%$ level.

[Table 11 about here]

\subsection{A second benchmark change in 2014}

In Section 3.1.1 we run 656 placebo regressions and show that the t-statistics obtained from the regressions around the actual benchmark change stand out as the most negative ones. In this section we present an additional analysis that can also be seen as a placebo exercise.

On February 17, 2014, the Exchange implemented a second change in the loan fee benchmark, reducing the moving-average window even further, from three days to one day; i.e., from that date onwards, the Exchange began to inform to the public the last day (volumeweighted) average of the loan fees across all loan deals for each stock. However, as we show, this last marginal benchmark change had a very small effect on short-sellers' predictive power over current loan fees. Moving from three to one day was almost immaterial in terms of prediction errors of current loan fees. As such, we should find no effect of this second 
benchmark change on loan fee levels. This additional placebo exercise is interesting to the extent that it was also a benchmark change announced by the Exchange, such as the one in 2011. As such, both events are comparable in terms of unobservables that could contribute to the obtained results (e.g., loan fees may become more salient for short-sellers when the Exchange announces a benchmark change).

We evaluate the 2014 benchmark change by taking advantage of the dataset used in Chague, De-Losso, and Giovannetti (2019), which goes from 2012 to $2014 .{ }^{9}$ As in our main analysis, we focus on stocks for which there was no payment of dividends of the type "Interests on equity" around the benchmark change (between January and March 2014); there are 61 different stocks. ${ }^{10}$

We first show that the 2014 change did not improve short-sellers' predictive power over current loan fees with the same intensity as the 2011 change. As in Section 2.2, we use both benchmarks for stock $s$ available on day $t$ as predictors for the (value- and equal-weighted) average loan fee of stock $s$ on day $t$ and compare their MSE and MAE values during the complete period from January 2012 to December 2014. When considering the daily valueweighted average loan fee as the predicted variable, the MSE under the one-day benchmark is $91 \%$ of the one under the three-day benchmark, and the MAE under the one-day benchmark is $92 \%$ of the one under the three-day benchmark (for the 2011 change, these ratios are $65 \%$ and $84 \%$, respectively, as reported in Section 2.2). When considering the daily equalweighted average loan fee as the predicted variable, the MSE under the one-day benchmark is $88 \%$ of the one under the three-day benchmark, and the MAE under the one-day benchmark is $93 \%$ of the one under the three-day benchmark (for the 2011 change, these ratios are $66 \%$ and $89 \%$, respectively, as reported in Section 2.2). That is, the relative increase in the price transparency was greater in the 2011 change, when the moving-average window was

\footnotetext{
${ }^{9}$ The dataset used in Chague, De-Losso, and Giovannetti (2019) contains all loan contracts closed in Brazil from January 2012 to December 2014. It comes from "Comissão de Valores Mobiliário" (CVM), the regulator of the Brazilian market. The dataset from Chague, De-Losso, Genaro, and Giovannetti (2017), used in the rest of this paper, comes from the Exchange.

${ }^{10}$ These are the stocks which, besides not having payment of dividends of the type "Interests on equity", display lending activity everyday between January and March 2014, with at least 10 loan deals per day.
} 
reduced from 15 to three days, than in the 2014 change, when the moving-average window was further reduced from three days to one day.

Next, as in Section 3.1, we run regression 1 using all loan deals closed from January 17, 2014 to March 17, 2014 (20 trading days before and 20 trading days after the benchmark change), setting the dummy variable After to be one between February 17, 2014 and March 17, 2014. Table 12 presents the results. In all columns, we find the coefficient on the timetrend break to be zero. That is, we cannot claim that the 2014 change in the benchmark significantly affected the loan fees.

[Table 12 about here]

\section{$5 \quad$ Loan fee benchmarks in other countries}

The previous results indicate that loan fee benchmarks should be beneficial to equity lending markets, consistent with the prediction by DDZ. Surprisingly, most countries do not have a loan fee benchmark available for their investors.

We collected information about the Financial Market Infrastructure (FMI) ${ }^{11}$ in 18 different countries ${ }^{12}$ to see whether there is either a publicly available benchmark or another disclosure regarding securities lending transactions. In only three of these 18 countries (India, Singapore, and Taiwan) short-sellers have access to some version of a loan fee benchmark. Surprisingly, in 15 countries (Australia, Belgium, Finland, France, Germany, India, Ireland, Japan, Singapore, Sweden, Switzerland, Taiwan, and the UK) at least part of the equity lending and registration rules are standardized, defined and implemented by the FMI itself. Therefore, for these countries, it would be quite feasible for the FMI to provide publicly available reference rates to the market. Appendix A.3 presents the details of the equity lending market in each country.

\footnotetext{
${ }^{11}$ Financial Market Infrastructure (FMI) refers to critically important institutions responsible for providing clearing, settlement and recording of monetary and other financial transactions.

${ }^{12}$ Australia, Belgium, Finland, France, Germany, India, Ireland, Japan, Malaysia, the Netherlands, New Zealand, Singapore, South Korea, Sweden, Switzerland, Taiwan, the US, and the UK.
} 


\section{Conclusion}

In recent research Duffie, Dworczak, and Zhu (2017) show that benchmarks can provide valuable pre-trade price information in OTC markets. Good benchmarks mitigate search frictions by lowering the informational asymmetry among market participants. In this paper we study the effects of a benchmark improvement that occurred in the Brazilian equity lending market in 2011. We take advantage of a very detailed dataset that includes all loan deals in the Brazilian market from July 2008 to July 2011.

We perform different analyses to empirically assess how the loan fee benchmark change affected the equity lending market, motivated by the predictions in Duffie, Dworczak, and Zhu (2017). We find that loan fees fall, lending volume increases, total lending revenue remains stable, and high-cost lenders lose market share after the benchmark change. Moreover, we also find that stock price efficiency increases with the benchmark change, what is consistent with the literature that relates greater short-selling restrictions (e.g., higher loan fees) with lower price efficiency (Bris, Goetzmann, and Zhu, 2007, Saffi and Sigurdsson, 2011, Boehmer and $\mathrm{Wu}, 2013)$.

Despite the potential benefits of loan fee benchmarks in equity lending markets, they are, in general, not available around the world. Across the 18 different countries that we evaluate, in only three (India, Singapore, and Taiwan) short-sellers have access to some type of loan fee benchmark. As such, we believe that our results may be relevant for regulators and practitioners. 


\section{References}

Aquilina, Matteo, and F. Andrea Pirrone, 2020, The effects of regulating benchmarks, Economics Letters 186, 108512.

Asquith, Paul, Thom Covert, and Parag Pathak, 2013, The Effects of Mandatory Transparency in Financial Market Design: Evidence from the Corporate Bond Market, Working Paper.

Asquith, Paul, Parag A. Pathak, and Jay R. Ritter, 2005, Short interest, institutional ownership, and stock returns, Journal of Financial Economics 78, 243 - 276.

Asriyan, Vladimir, William Fuchs, and Brett Green, 2017, Information spillovers in asset markets with correlated values, American Economic Review 107, 2007-40.

Back, Kerry, Ruomeng Liu, and Alberto Teguia, 2020, Signaling in otc markets: Benefits and costs of transparency, Journal of Financial and Quantitative Analysis 55, 47-75.

Barbosa, Fernando, Marco Bonomo, Joao De Mello, and Lira Mota, 2018, Short-selling restrictions and returns: A natural experiment, Working Paper.

Bessembinder, Hendrik, William Maxwell, and Kumar Venkataraman, 2006, Market transparency, liquidity externalities, and institutional trading costs in corporate bonds, Journal of Financial Economics 82, 251-288.

Blocher, Jesse, Adam V. Reed, and Edward D. Van Wesep, 2013, Connecting two markets: An equilibrium framework for shorts, longs, and stock loans, Journal of Financial Economics 108, 302-322.

Boehmer, Ekkehart, Truong X. Duong, and Zsuzsa R. Huszar, 2018, Short covering trades, Journal of Financial and Quantitative Analysis 53, 723-748.

Boehmer, Ekkehart, and Juan (Julie) Wu, 2013, Short Selling and the Price Discovery Process, Review of Financial Studies 26, 287-322. 
Bris, Arturo, William N. Goetzmann, and Ning Zhu, 2007, Efficiency and the Bear: Short Sales and Markets Around the World, Journal of Finance 62, 1029-1079.

Cao, Bing, Dan S. Dhaliwal, Adam C. Kolasinski, and Adam V. Reed, 2007, Bears and Numbers: Investigating How Short Sellers Exploit and Affect Earnings-Based Pricing Anomalies, Working Paper.

Chague, Fernando, Rodrigo De-Losso, Alan Genaro, and Bruno Giovannetti, 2017, Wellconnected short-sellers pay lower loan fees: A market-wide analysis, Journal of Financial Economics 123, 646-670.

Chague, Fernando, Rodrigo De-Losso, and Bruno Giovannetti, 2019, The short-selling skill of institutions and individuals, Journal of Banking 8 Finance 101, 77-91.

Chang, Eric, Joseph W. Cheng, and Yingchui Yu, 2007, Short-Sales Constraints and Price Discovery: Evidence from the Hong Kong Market, Journal of Finance 62, 2097-2121.

Danielsen, Bartley R., and Sorin M. Sorescu, 2001, Why Do Option Introductions Depress Stock Prices? A Study of Diminishing Short Sale Constraints, The Journal of Financial and Quantitative Analysis 36, 451-484.

Diether, Karl B., Kuan-Hui Lee, and Ingrid M. Werner, 2009, Short-Sale Strategies and Return Predictability, Review of Financial Studies 22, 575-607.

Duffie, Darrell, 2018, Financial regulatory reform after the crisis: An assessment, Management Science 64, 4835-4857.

Duffie, Darrell, Piotr Dworczak, and Haoxiang Zhu, 2017, Benchmarks in search markets, Journal of Finance 72, 1983-2044.

Duffie, Darrell, Nicolae Garleanu, and Lasse Heje Pedersen, 2002, Securities lending, shorting, and pricing, Journal of Financial Economics 66, 307 - 339. 
Edwards, Amy K, Lawrence E Harris, and Michael S Piwowar, 2007, Corporate bond market transaction costs and transparency, Journal of Finance 62, 1421-1451.

Engelberg, Joseph E., Adam V. Reed, and Matthew C. Ringgenberg, 2012, How are shorts informed?: Short sellers, news, and information processing, Journal of Financial Economics $105,260-278$.

Evans, Richard, Miguel A. Ferreira, and Melissa Porras Prado, 2017, Fund Performance and Equity Lending: Why Lend What You Can Sell?, Review of Finance 21, 1093-1121.

Goldstein, Michael A, Edith S Hotchkiss, and Erik R Sirri, 2006, Transparency and liquidity: A controlled experiment on corporate bonds, Review of Financial Studies 20, 235-273.

Hou, Kewei, and Tobias J. Moskowitz, 2005, Market Frictions, Price Delay, and the CrossSection of Expected Returns, The Review of Financial Studies 18, 981-1020.

Huszár, Zsuzsa R., and Melissa Porras Prado, 2019, An analysis of over-the-counter and centralized stock lending markets, Journal of Financial Markets 43, 31-53.

Jones, Charles M., and Owen A. Lamont, 2002, Short-sale constraints and stock returns, Journal of Financial Economics 66, 207 - 239.

Kolasinski, Adam C., Adam V. Reed, and Matthew C. Ringgenberg, 2013, A Multiple Lender Approach to Understanding Supply and Search in the Equity Lending Market, Journal of Finance 68, 559-595.

Nagel, Stefan, 2005, Short sales, institutional investors and the cross-section of stock returns, Journal of Financial Economics 78, 277 - 309.

Prado, Melissa, Pedro A. C. Saffi, and Jason Sturgess, 2016, Ownership Structure, Limits to Arbitrage, and Stock Returns: Evidence from Equity Lending Markets, The Review of Financial Studies 29, 3211-3244. 
Rapach, David E., Matthew C. Ringgenberg, and Guofu Zhou, 2016, Short interest and aggregate stock returns, Journal of Financial Economics 121, 46-65.

Saffi, Pedro A. C., and Kari Sigurdsson, 2011, Price Efficiency and Short Selling, Review of Financial Studies 24, 821-852.

Schultz, Paul, and Zhaogang Song, 2019, Transparency and dealer networks: Evidence from the initiation of post-trade reporting in the mortgage backed security market, Journal of Financial Economics 133, 113 - 133.

Stambaugh, Robert F., Jianfeng Yu, and Yu Yuan, 2012, The short of it: Investor sentiment and anomalies, Journal of Financial Economics 104, 288-302. 


\section{A Appendix}

\section{A.1 Equity lending in Brazil}

Trading in the equity loan market in Brazil is over-the-counter (OTC), as in the US. Unlike the US, however, all loan contracts must be registered with B3, the exchange, the only stock exchange in Brazil. B3 acts as a clearing platform, and as a central counterparty. It guarantees all loan contracts and keeps track of the contract collateral. Hence, although investors face an opaque market as in the US, researchers have access to market-wide data, observing every single transaction.

The way the equity lending market works in Brazil is very similar to the US. Securities lenders earn a freely negotiated fee for lending securities. The fee is paid to lenders net of income withholding tax. A borrower is required to pay both the lender's fee and a transaction fee owed to B3. Currently, this transaction fee is charged at a rate of $0.25 \%$ per year calculated on the loan amount, i.e., the financial value of the borrower's open interest position, provided a minimum $\mathrm{R} \$ 10.00$ fee applies. Where the automatic securities lending program is activated, the transaction fee is charged at $0.50 \%$ per year and no minimum fee applies.

There are two types of standard settlement arrangements, which are related to the contract term and right of early return or recall (if any), as follows:

- Returnable: For loans that include an early return option, settlement may take place sooner than anticipated if the borrower chooses to return equivalent securities to the lender earlier

- Returnable/recallable: For loans that include both an early return option and a recall option, settlement may take place sooner than anticipated either because the borrower chooses to exercise the early return option, or otherwise because the lender recalls equivalent securities from the borrower. 
Early return by the borrower may be executed up to 7:00 p.m and including one business day prior to the expiration date. In this case, the borrower shall fully or partially settle the contract by 8:00 p.m. On the expiration date of the contract or on the expiration date of the request for early settlement by the lender, full or partial settlement shall be executed by 8:00 p.m. Early settlement by the lender follows the procedure above: for requests made up to 9:30 a.m the borrower must execute settlement of the contract by 8:00 p.m. of $\mathrm{T}+3$ from the request date; for requests made after 9:30 a.m. the borrower must execute settlement by 8:00 p.m. of $\mathrm{T}+4$ from the request date.

When a security is lent, the title and the ownership are transferred to the borrower, such that the issuer will not be making direct payments to the lender. However, the borrower refunds the lender (and the securities lending system is programmed to process the refund) for payouts, at the same amounts and dates as cash distributions are paid out by the issuer. This means that at the payment date set by the issuer, the system will credit the lender for the payout amount (as adjusted to account for any withholding tax charges). Based on the premise of making the lender "whole" for any corporate action event, in the case of cash distributions (e.g., interest on capital, dividends), the lender retains right to be paid cash in the equivalent of any payouts, as if the securities were not on loan. Where a corporate action event affects the number of outstanding securities of the issuer (e.g., bonus stock distributions, stock splits, reverse splits), the number of securities delivered to the lender at the end of the loan will have been adjusted to account for the effects of the relevant corporate action event. However, the voting rights inherent in shares on loan are not retained by a lender; rather, they are transferred to the borrower along with the title and ownership.

At the outset of a loan, the borrower is required to post collateral for $100 \%$ of the principal amount of the loan (value of the loaned securities) plus an amount to cover potential exposure to future fluctuations in the market price of the security. The value of such additional amount, called margin interval, depends on the outcome of risk assessments made by B3, which take into account stress scenarios estimated to the relevant security. The margin 
interval, which generally ranges between $15 \%$ and $100 \%$ of the principal, represents the prospective price fluctuation of the security over two consecutive trading sessions. Clearing agents admitted as participants of B3 bear co-responsibility with customer borrowers for loan settlement. At the clearing agent's discretion, this may lead the clearing agent to require additional collateral from a customer borrower. Before taking a loan position, the lender must have placed the securities in custody at B3's Central Securities Depository. Similarly, before taking a borrowing position, the borrower must have posted the required collateral (pre-margining system). During the life of the loan, daily margin calls may be made as a result of mark-to-market adjustments to the value of the loan. For example, if the market price for the security rises, the borrower will be required to make an additional margin deposit.

A difference with respect to the US is the way loan fees are quoted in Brazil. In the US, the loan fee is implicitly given by the "rebate" rate when loans are cash-collateralized. The rebate rate is the interest rate that the lender pays the borrower in exchange for holding the cash-collateral; it is lower than the fed funds rate. The higher the difference between the rebate rate and the fed funds rate, the higher the implicit loan fee. If the borrower posts instead Treasury securities as collateral, she simply pays the lender an explicit loan fee. Since in Brazil all loan deals are collateralized with Treasury securities, there are no "rebate" rates and all loan deals are always negotiated in terms of explicit loan fees.

\section{A.2 BMF\&Bovespa External Communication}

Below is a facsimile of the announcement of the change in the loan fee benchmark 


\section{BM\&FBOVESPA}

A Nova Bolsa

February 23, 2011

013/2011-DN

\section{EXTERNAL COMMUNICATION}

To: The BM\&FBOVESPA (BVMF) Market Participants - Bovespa Segment

\section{Re: Changes to the Publication of Fees on Registered Loans at the} Securities Lending Service (BTC).

We hereby inform you that as of March 1, 2011, the average fees on registered loans at the BTC will be published on the internet based on a 3 (three) business day period per security. At present the published period is for 15 (fifteen) business days.

We highlight that the purpose of this change is to make the securities lending service ever more transparent, in order to attract more securities lenders and borrowers and to meet the demand of institutional investors.

For further information about securities lending please click on www.cblc.com.br/cblc/ingles $>$ Securities Lending Program $>$ Consult $>$ Registered Loan.

José Antonio Gragnani

Chief Business Development Officer

BM\&FBOVESPA S.A. - Bolsa de Valores, Mercadorias e Futuros Praça Antonio Prado, 48 - 01010-901 - São Paulo, SP

Tel.: (11) 2565-4000 - Fax (11) 2565-7737

wwrw.bmfbovespa.com.br 
This table describes the equity lending market in 18 different countries (Australia, Belgium, Finland, France, Germany, India, Ireland, Japan, Malaysia, Netherlands, New Zealand, Singapore, South Korea, Sweden, Switzerland, Taiwan, United Kingdom, and United States) and identifies whether there is either a publicly available benchmark or fully disclosure information regarding securities lending transactions. The sources of information are Huszár and Prado (2019) and the institutions websites indicated below.

Exchange Country Description of the lending market_Benchmark

SGX Singapore The Central Depository (CDP) is a subsidiary of the Singapore Stock Exchange (SGX). It offers clearing, settlement, depository, securities, investment strategies, financial planning, and advisory services. The Securities Borrowing and Lending (SBL) service has over $80 \%$ of the total listed

Yes, all the standardized stocks on SGX available for lending and borrowing via Central Depository. All the loan fees are loan fees are available online.

co standardized (4\% to lenders and $6 \%$ to borrowers). Starting 2 Dec 2019, these fees will vary according to factors such as the supply and demand of the securities. Lenders will get a fixed $70 \%$ of the borrowing fee, which is higher than the current $66.67 \%$. (source: SGX website https://www1.cdp.sgx.com/sgx-cdp-web/lendingpool/show)

TWSE Taiwan The Taiwan Stock Exchange acts as the clearinghouse for all trades executed in the TWSE's market. The TWSE centralized SBL system provides three types of transactions: fixed-rate, competitive bid and negotiated transaction. The negotiated transaction mode accounted for $72.5 \%$ of all transactions in 2017. (sources: TWSE SBL System Overview \& Publications https://www.twse.com.tw/en/page / products/sbl/edu.html, https://mis.twse.com.tw/stock/sblinquiry.jsp and https://www.twse.com.tw/en/page/trading/SBL/t13sa710.html) and within market quotes there is the SBL fees transacted.

NSE India

The National Stock Exchange of India (NSE) offers SBL through the clearing corporation/clearing house of stock exchanges. Lending \& Borrowing is facilitated on an automated screen-based platform where the order matching is on price time priority. The participant needs to quote the lending fee per share on the order matching platform. (source: NSE website https://www.nseindia.com/products/content/ equities/slbs/slbs.htm)
Yes, NSE provides on a daily basis information regarding loan fees, number of trades and financial amount. 
(...continued from previous page)

Exchange Country Description of the lending market

Benchmark

Clearstream Germany, Eurex Clearing and Clearstream jointly offer a centrally cleared securities lending product.

No.

Eurex Switzer- Clearstream arranges the loans between the borrower and the lender as a neutral agent. While

Clearing land the bilateral negotiation is managed by Clearstream, the actual trading is done anonymously on the electronic Eurex Repo platform. On the clearing side, the central counterparty Eurex

Clearing then novates the trade and performs the exchange of the loan against the collateral. In doing so, Eurex Clearing is the legal counterparty to the clearing members on the borrowing and the lending side at loan level. Clearstream then manages the collateral in its function as a neutral triparty collateral agent. (source: Eurex clearing website,

https://www.eurexclearing.com/clearing-en/about-us/company-profile)

OCC USA
The Options Clearing Corporation (OCC) makes two stock loan programs available to its Clearing Members; the OCC Stock Loan/Hedge Program and the OCC Market Loan Program. The first was created in 1993 by OCC to clear and guarantee, because OCC acts as a central counterparty ("CCP"), stock loan transactions between Clearing Members. In the second, OCC currently clears securities lending transactions for Automated Equity Finance Markets, Inc., a wholly owned subsidiary of EquiLend Clearing LLC (ECS). ECS matches lenders and borrowers in an exchange-like platform using automated liquidity and price discovery mechanisms. (sources: OCC Website, https://www.theocc.com/clearing/clearing-services/stock-loan.jsp and https://www.theocc.com/webapps /stock-loan-volume)
No, there is only information for the loan transaction volume.

\footnotetext{
Bursa Malaysia Bursa Malaysia offers two models of Securities Borrowing and Lending (SBL): the Central

Malaysia

Lending Agency (CLA) and the Negotiated Transaction (NT). In the first, Bursa Malaysia acts

as the CLA for all SBL transactions between lenders and borrowers, which must comply with

Bursa Clearing's Terms and Conditions. In the second, approved lenders and borrowers can agree

to their own SBL terms and conditions and report such transactions to Bursa Malaysia. (source:

Bursa Malaysia website

http://www.bursamalaysia.com/market/products-services/securities-borrowing-lending-sbl/\#)
} 


$\begin{array}{lll}\text { NZCDC New } & \text { New Zealand Clearing and Depository Corporation Limited (NZCDC) offers a securities lending } & \text { No. } \\ \text { Zealand } & \text { facility for Depository Participants. The Clearing House acts as the central counterparty for all } \\ & \text { securities lending transactions initiated through the Depository. The securities lending facility } \\ \text { provides Depository Participants an opportunity to lend securities held in the Depository. } & \\ & \text { Clearing Participants, given the provision of adequate collateral, are eligible to borrow securities } \\ & \text { from the lending pool. (source: NZCDC website, } \\ & \text { https://www.nzx.com/services/nzx-clearing/faq) }\end{array}$

ASX Australia The Central Securities Depository (CSD) is one of Australia's most important settlement and depository systems, holding more than $95 \%$ of Australian fixed income securities and more than $85 \%$ of commercial paper. ASX Collateral, ASX's Centralized Securities Depository (CSD) tri-party collateral management service, is the only live, fixed income, tri-party repo securities lending and collateral management service provider in Australia that mobilizes collateral directly within the CSD. The service collateralizes exposures across a range of products, including SBL. (source: ASX website,

https://www.asx.com.au/services/information-services/securities-lending-disclosure.htm)
No, the ASX has a "Securities lending disclosure" section with a variety of reports, but no information on loan fees transacted. manage securities and collateral, which include KSD, Korea Securities Finance Corporation (KSFC), and some securities companies. Domestic stock lending is usually made through KSD, while bond lending is usually made through KSFC. The borrower and the lender choose the type of transaction and enter application details (quantity, fees, etc.) into web-based KSD SLB system, which acts as the intermediary of the whole transaction. (source: KSD website, https://ksd.or.kr/eng/static/EB050200 0000.home?-menuNo=69 and http://freesis.kofia.or.kr/)
}

No, there is only information for the loan transaction volume published by the Korea Financial Investment Association (KOFIA). 
(...continued from previous page)

Exchange Country Description of the lending market

Benchmark

Euroclear UK, Euroclear's offers a securities lending and borrowing program. In it, there is no direct $\quad$ No

Ireland, relationship between lenders and borrowers. Instead, participants have a contractual relationship

Belgium, with Euroclear, which takes the exposure risk. The name and positions of the counterparties are

Finland, not disclosed. Lenders' positions are aggregated into an anonymous 'lending pool' from which

Nether- securities are allocated to borrowers. (source: Euroclear Website,

lands, https://www.euroclear.com/services/en/securities-lending-and-borrowing.html)

空

France,

Sweden.

The Japan Securities Finance Co. (JSF) acts as an intermediary in the lending stock business. The intermediation between stock lenders and stock borrowers is done through the JSF which centralizes the stock transfers, the collateral and the negotiated fee.
No fully publicly available, but there is a third-party paid solution (Apex JSFC Trade Manager) sponsored by the JSFC which provides the previous five days fee paid for the same security. 

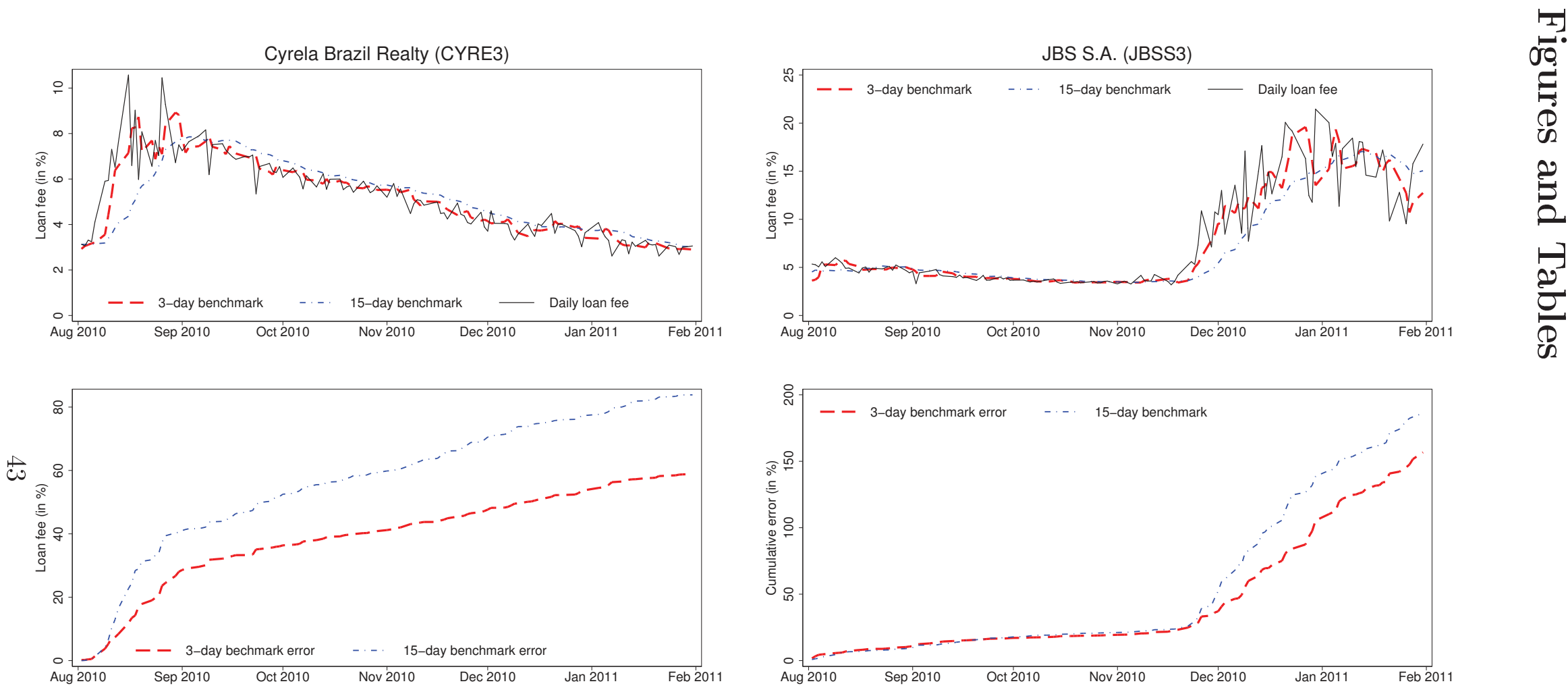

Figure 1: Informational gain from new benchmark

These graphs present a comparison of the old 15-day benchmark (computed as the average loan fee over the previous 15 trading days) with the new 3 -day benchmark (computed over the previous 3 trading days) for two stocks arbitrarily chosen. We reconstruct the benchmarks using our data over the six month period prior to the implementation of the new benchmark and compare them with the actual daily average loan fee. The lower row presents the errors incurred in using the benchmarks to predict current loan fees and accumulate the absolute errors over time. 


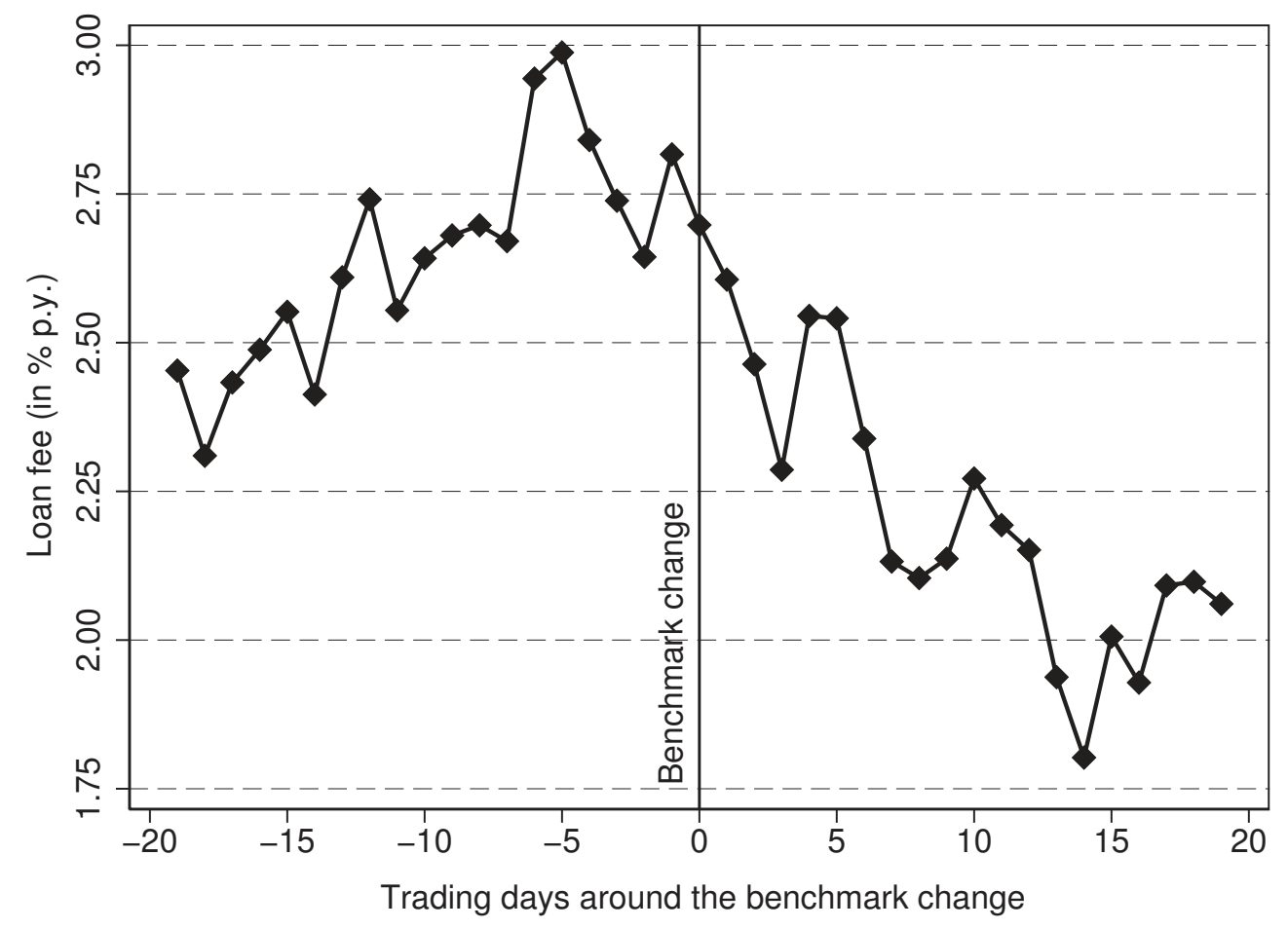

Figure 2: Evolution of loan fees around the benchmark change

The graph shows the average daily loan fee across all stocks in \%, per year. We first compute the average loan fee for each stock-day. We then compute the average of this variable across all stocks for each day. 


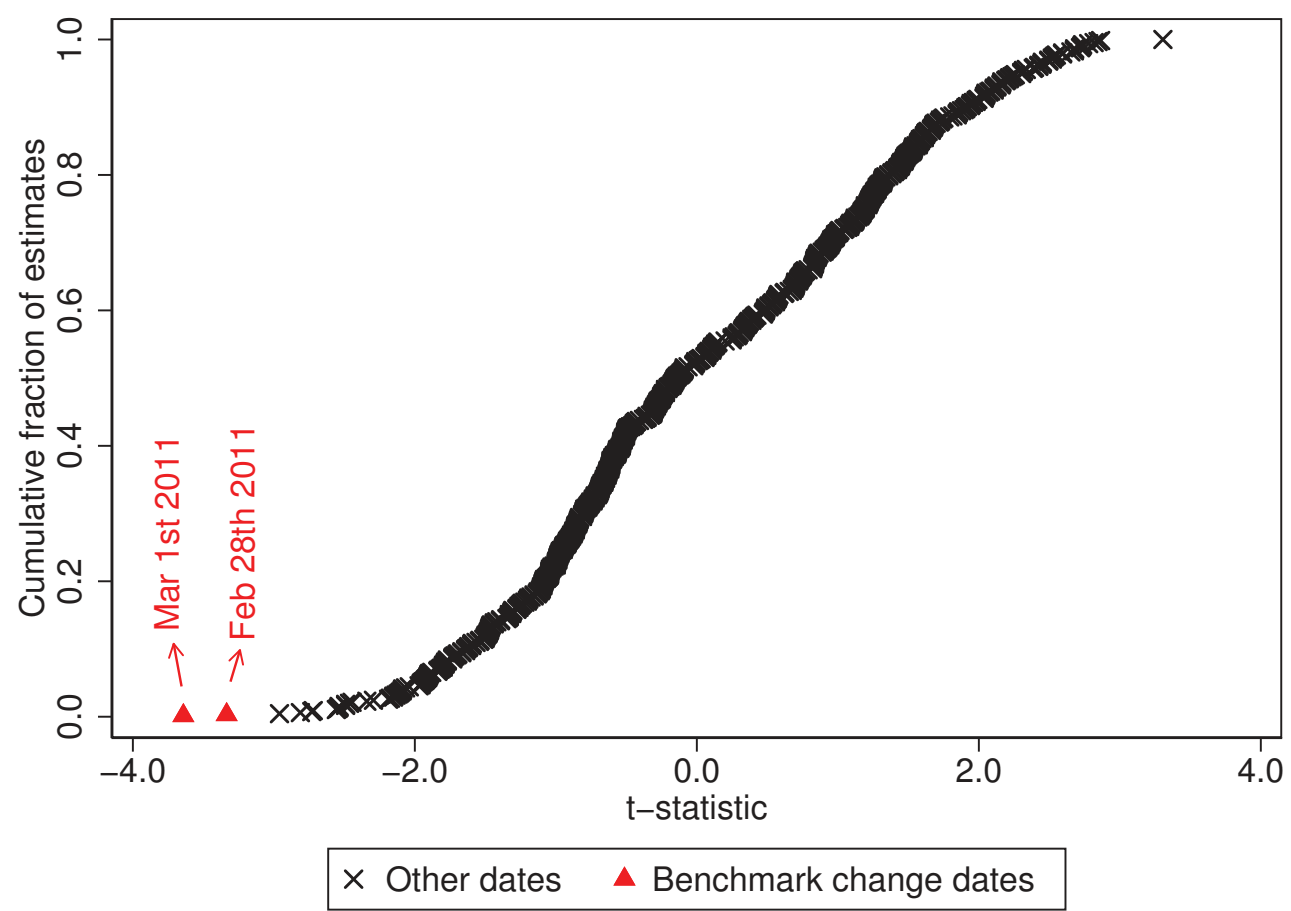

Figure 3: T-statistics using different samples

The graph shows the t-statistics estimated from all possible 40-day rolling window samples starting from July 2008 until March 2011 of $\beta_{2}$ in the regression Fee $_{s, t}=\beta_{0}+\beta_{1} t+\beta_{2} t \times A f t e r_{t}+\boldsymbol{\beta}_{3}^{\prime} \boldsymbol{X}_{\boldsymbol{s}, t}+\alpha_{s}+\varepsilon_{s, t}$, where $t$ is a linear time trend, After $t_{t}$ is a dummy variable that is zero in the first 20 days of the sample and one in the last 20 days on the sample, $\boldsymbol{X}_{s, t}$ is a vector of controls containing i) the stock return over the last the 5 days, ii) the stock return over the last the 240 days, and iii) the standard deviation of daily stock returns computed using the last 15 days, and $\alpha_{s}$ are stock fixed effects. There are in total 656 different t-statistics of the $\beta_{2}$ coefficient, one for each rolling sample. The red triangles denote the t-statistics estimated around the benchmark change. T-statistics are sorted by magnitude. 


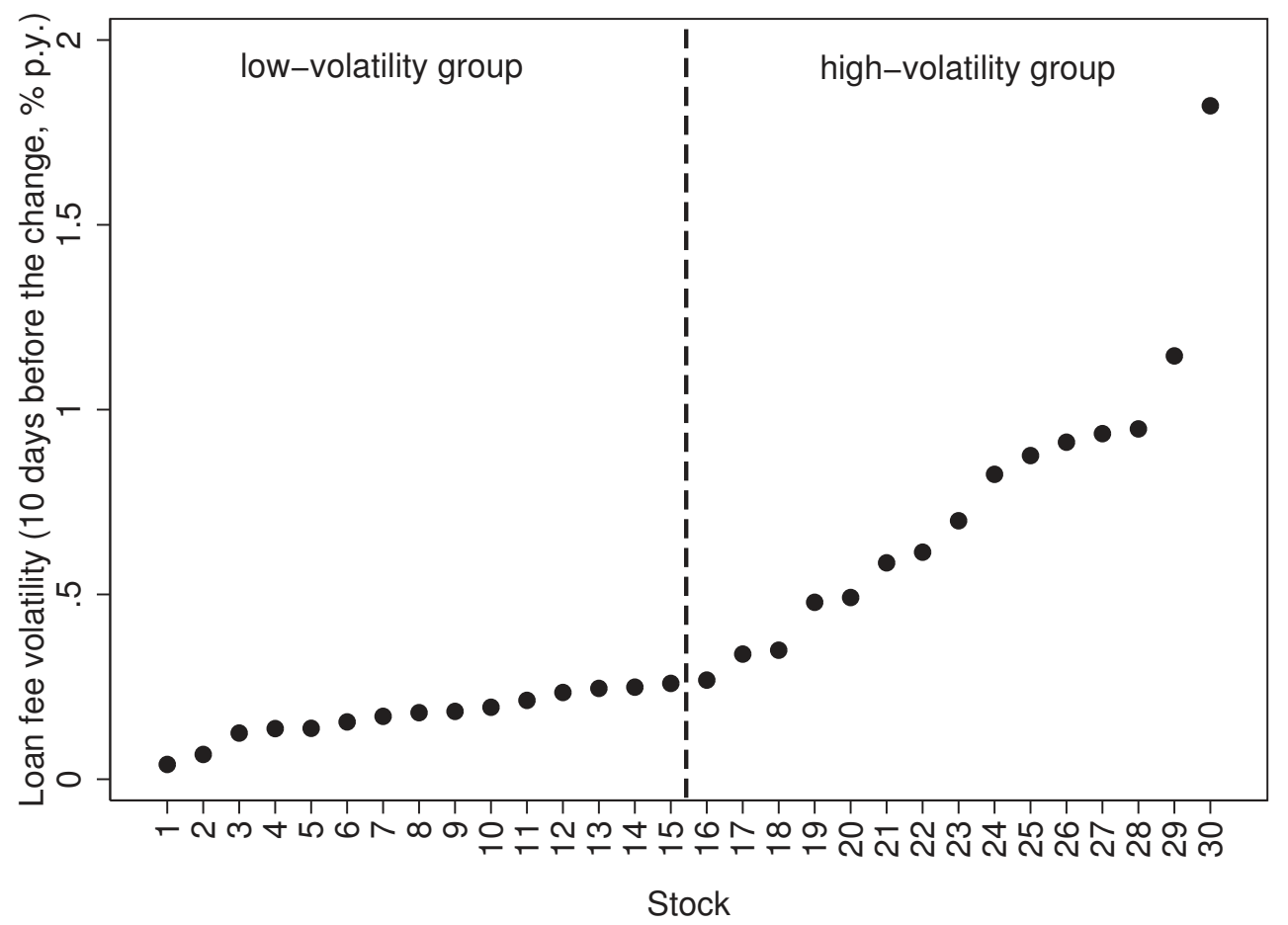

Figure 4: The loan fee volatility of each stock before the benchmark change This graph shows the loan fee volatility of each stock during the 10-day period just before the benchmark change. We first compute the average loan fee of each stock on each day $\left(\overline{F e e}_{s, t}\right)$, and then compute for each stock the standard deviation of $\overline{F e e}_{s, t}$ during the 10-day period just before the benchmark change. We rank the stocks according to these standard deviations and split them into two groups of 15 stocks each. 


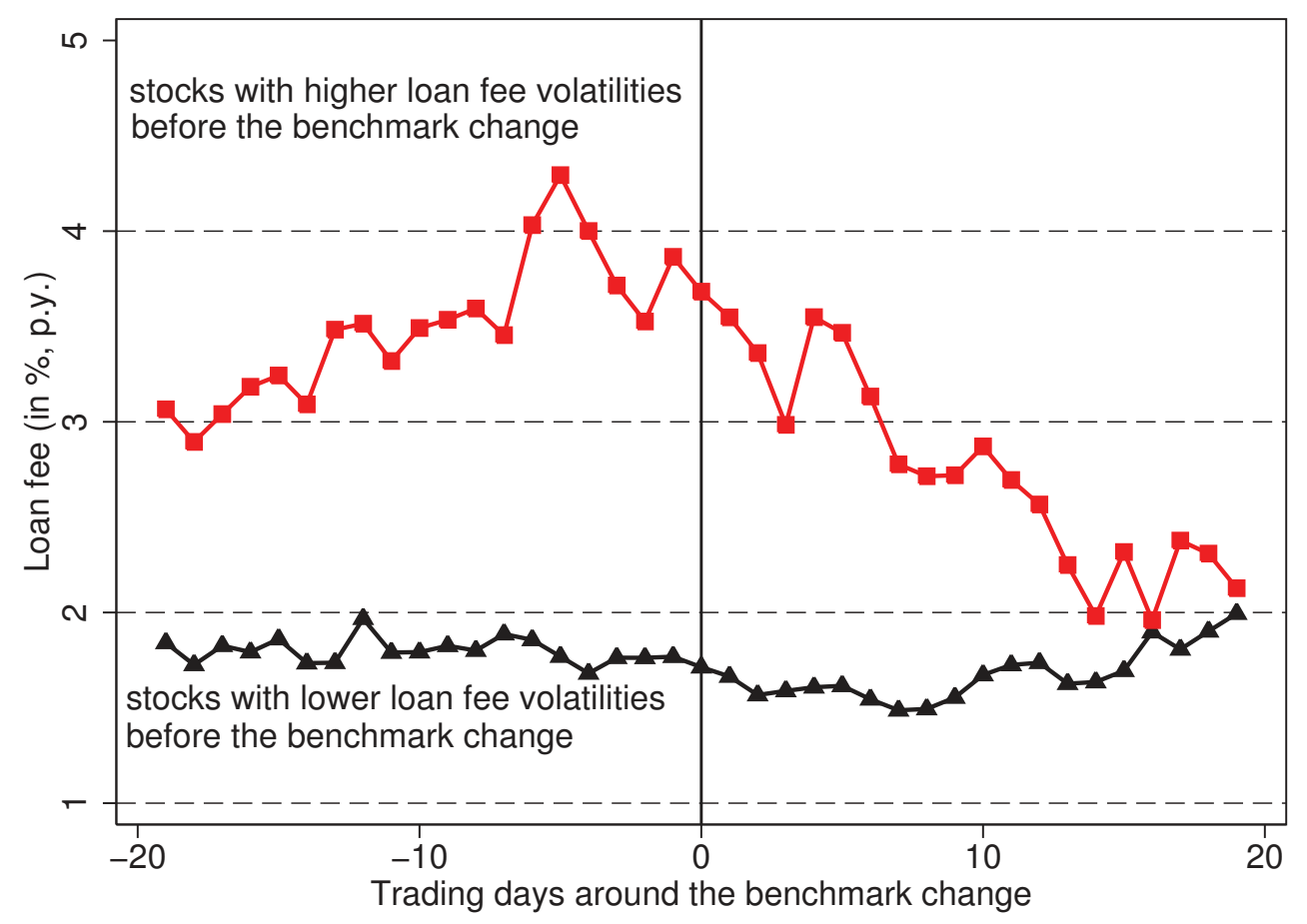

Figure 5: Evolution of loan fees around the benchmark change: Heterogeneous effects The graph shows the average daily loan fee (in \%, per year) across the 15 stocks with low loan fee volatility before the benchmark change (black line with triangles) and across the 15 stocks with high loan fee volatility before the benchmark change (red line with squares). To split the stocks into the two groups we first compute the average loan fee of each stock on each day $\left(\overline{F e e}_{s, t}\right)$, and then compute for each stock the standard deviation of $\overline{F e}_{s, t}$ during the 10-day period just before the benchmark change. We rank the stocks according to these standard deviations and split them into two groups of 15 stocks each. 
Table 1: Descriptive statistics

This table presents the following descriptive statistics for each stock: the market capitalization at the end of January of 2011 (US $\$$ billion), the average daily lending volume (in US $\$$ million) before (February 2011) and after (March 2011) the benchmark change, and the average loan fee (in bps, per year) before and after the benchmark change.

Average daily volume (in US\$ million)

Average loan fee (in bps, per year)

\begin{tabular}{|c|c|c|c|c|c|c|c|c|}
\hline & $\begin{array}{c}\text { Stock } \\
(1)\end{array}$ & $\begin{array}{c}\text { Mkt. cap. } \\
\text { (US\$ billion) } \\
(2)\end{array}$ & $\begin{array}{c}\text { A } \\
\text { Feb } \\
(3)\end{array}$ & $\begin{array}{c}\text { B } \\
\text { Mar } \\
(4) \\
\end{array}$ & $\begin{array}{c}100 \times(\mathrm{B}-\mathrm{A}) / \mathrm{A} \\
(5)\end{array}$ & $\begin{array}{c}\text { A } \\
\text { Feb } \\
(6) \\
\end{array}$ & $\begin{array}{c}\text { B } \\
\text { Mar } \\
(7) \\
\end{array}$ & $\begin{array}{c}B-A \\
(8) \\
\end{array}$ \\
\hline 1 & AMBV4 & 36.2 & 385.69 & 521.36 & 35.17 & 28.02 & 30.32 & 2.31 \\
\hline 2 & BBDC4 & 34.7 & 590.00 & 656.43 & 11.26 & 55.63 & 59.65 & 4.02 \\
\hline 3 & BRAP4 & 6.3 & 50.30 & 61.69 & 22.65 & 39.34 & 27.50 & -11.84 \\
\hline 4 & BRKM5 & 4.4 & 71.79 & 87.78 & 22.28 & 129.04 & 142.65 & 13.61 \\
\hline 5 & BRML3 & 3.8 & 37.52 & 30.94 & -17.55 & 301.06 & 270.19 & -30.87 \\
\hline 6 & BTOW3 & 1.9 & 49.27 & 119.45 & 142.46 & 254.42 & 205.48 & -48.94 \\
\hline 7 & CCRO3 & 12.4 & 57.32 & 61.51 & 7.30 & 90.10 & 71.30 & -18.81 \\
\hline 8 & CESP6 & 3.6 & 22.36 & 23.89 & 6.83 & 99.81 & 72.70 & -27.11 \\
\hline 9 & CMIG4 & 6.2 & 150.73 & 130.19 & -13.62 & 202.48 & 253.26 & 50.78 \\
\hline 10 & CPFE3 & 11.9 & 92.36 & 115.10 & 24.62 & 594.63 & 629.41 & 34.79 \\
\hline 11 & CPLE6 & 3.2 & 62.02 & 57.03 & -8.05 & 153.75 & 66.97 & -86.78 \\
\hline 12 & CSAN3 & 6.5 & 59.70 & 65.16 & 9.14 & 85.73 & 87.08 & 1.35 \\
\hline 13 & CSNA3 & 24.7 & 129.85 & 181.35 & 39.67 & 50.90 & 35.30 & -15.59 \\
\hline 14 & CYRE3 & 4.8 & 206.78 & 197.01 & -4.72 & 265.38 & 144.37 & -121.01 \\
\hline 15 & ELET3 & 14.6 & 195.91 & 78.85 & -59.75 & 246.10 & 131.43 & -114.66 \\
\hline 16 & ELET6 & 4.3 & 316.20 & 223.92 & -29.19 & 527.69 & 658.27 & 130.59 \\
\hline 17 & ENBR3 & 3.5 & 2.86 & 9.76 & 241.19 & 521.63 & 468.69 & -52.94 \\
\hline 18 & GFSA3 & 2.7 & 210.66 & 217.32 & 3.16 & 82.39 & 121.24 & 38.85 \\
\hline 19 & GGBR4 & 13.4 & 463.29 & 624.16 & 34.72 & 159.57 & 264.59 & 105.02 \\
\hline 20 & GOAU4 & 4.3 & 29.41 & 31.83 & 8.22 & 27.32 & 23.46 & -3.87 \\
\hline 21 & GOLL4 & 1.9 & 57.18 & 40.94 & -28.39 & 86.40 & 79.93 & -6.47 \\
\hline 22 & JBSS3 & 9.6 & 75.28 & 85.75 & 13.90 & $1,209.18$ & 671.02 & -538.15 \\
\hline 23 & KLBN4 & 2.0 & 80.20 & 65.99 & -17.71 & 209.79 & 199.52 & -10.27 \\
\hline 24 & LIGT3 & 3.2 & 68.18 & 70.98 & 4.12 & 175.96 & 218.45 & 42.49 \\
\hline 25 & MRVE3 & 4.3 & 206.56 & 239.15 & 15.78 & 630.57 & 459.75 & -170.82 \\
\hline 26 & RDCD3 & 8.1 & 340.46 & 352.34 & 3.49 & 469.33 & 349.95 & -119.38 \\
\hline 27 & RSID3 & 2.2 & 102.98 & 142.67 & 38.54 & 176.08 & 141.21 & -34.87 \\
\hline 28 & SBSP3 & 5.7 & 34.28 & 38.00 & 10.85 & 385.19 & 232.88 & -152.31 \\
\hline 29 & SUZB5 & 2.3 & 19.49 & 41.53 & 113.11 & 406.96 & 397.37 & -9.59 \\
\hline 30 & TAMM4 & 2.2 & 91.51 & 116.06 & 26.83 & 300.07 & 197.98 & -102.08 \\
\hline \multicolumn{3}{|c|}{ cross-stock average } & 142.00 & 156.27 & 21.88 & 265.48 & 223.73 & -41.75 \\
\hline \multirow{2}{*}{\multicolumn{3}{|c|}{$\begin{array}{c}\text { cross-stock st. dev. } \\
\text { t-stat. }\end{array}$}} & 144.18 & 170.35 & 55.33 & 250.60 & 190.17 & 114.63 \\
\hline & & & & & $2.17=\frac{21.88}{55.33 / \sqrt{30}}$ & & & $-1.99=\frac{-41.75}{114.63 / \sqrt{30}}$ \\
\hline
\end{tabular}


Table 2: Benchmark effect on the loan fee level: Stock-day regressions (average and median loan fee)

This table presents the stock-day panel regression

$$
\phi_{s, t}=\beta_{0}+\beta_{1} t+\beta_{2} t \times \text { After }_{t}+\boldsymbol{\beta}_{\mathbf{3}}^{\prime} \boldsymbol{X}_{\boldsymbol{s}, \boldsymbol{t}}+\alpha_{s}+\varepsilon_{s, t}
$$

where $\phi_{s, t}$ is either the average loan fee (bps, per year) of stock $s$ on day $t$ (columns 1 to 3 ) or the median loan fee (bps, per year) of stock $s$ on day $t$

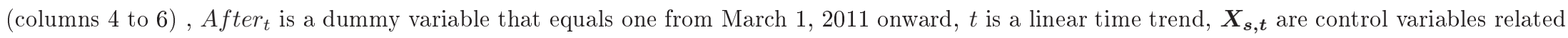
to stock $s$ on day $t$, and $\alpha_{s}$ are stock fixed effects. We include the following variables in $\boldsymbol{X}_{s, t}$ : i) the stock return over the last the 5 days, ii) the stock return over the last the 240 days, and iii) the standard deviation of daily stock returns computed using the last 15 days. Standard errors are clustered by stock and t-statistics are presented in parentheses. ${ }^{* * *},{ }^{* *}$, and $*$ indicate significance at the $1 \%, 5 \%$, and $10 \%$ levels, respectively.

\begin{tabular}{ccccccc} 
& \multicolumn{3}{c}{ Average loan fee } & \multicolumn{3}{c}{ Median loan fee } \\
& $(1)$ & $(2)$ & $(3)$ & $(4)$ & $(5)$ & $(6)$ \\
\hline Trend & 1.66 & 1.77 & 0.92 & 1.11 & 1.23 & 0.32 \\
& $(1.51)$ & $(1.10)$ & $(0.78)$ & $(1.05)$ & $(1.17)$ & $(0.28)$ \\
Trend×After & $-2.71^{* *}$ & $-2.75^{* *}$ & $-2.20^{* * *}$ & $-2.54^{* *}$ & $-2.58^{* *}$ & $-1.94^{* * *}$ \\
& $(2.72)$ & $(-2.71)$ & $(-3.78)$ & $(-2.49)$ & $(-2.49)$ & $(-3.72)$ \\
Ret[-5] & & & 1.65 & & & 1.66 \\
& & & $(0.81)$ & & & $(0.75)$ \\
Ret[-240] & & & -1.96 & & & -2.62 \\
& & & $-0.94)$ & & & $(-1.06)$ \\
Volatility[-10] & & & 4.56 & & & 12.51 \\
& & & $(0.31)$ & & & $0.80)$ \\
Constant & $249.11^{* * *}$ & $247.45^{* * *}$ & $259.89^{* * *}$ & $244.93^{* * *}$ & $243.07^{* * *}$ & $243.64^{* * *}$ \\
& $(5.47)$ & $(14.77)$ & $(7.41)$ & $(4.85)$ & $(19.05)$ & $(6.19)$ \\
Fixed effects & No & Stock & Stock & No & Stock & Stock \\
Observations & 1,163 & 1,163 & 1,163 & 1,163 & 1,163 & 1,163 \\
R2 & $0.97 \%$ & $82.42 \%$ & $82.64 \%$ & $1.31 \%$ & $81.28 \%$ & $81.64 \%$ \\
\hline \hline
\end{tabular}


Table 3: Benchmark effect on the loan fee level: Stock-day regressions (loan fee 5th and 95th percentiles)

This table presents the stock-day panel regression

$$
\phi_{s, t}=\beta_{0}+\beta_{1} t+\beta_{2} t \times \text { After }_{t}+\boldsymbol{\beta}_{\mathbf{3}}^{\prime} \boldsymbol{X}_{\boldsymbol{s}, t}+\alpha_{s}+\varepsilon_{s, t}
$$

where $\phi_{s, t}$ is either the 5 th percentile loan fee (bps, per year) of stock $s$ on day $t$ (columns 1 to 3 ) or the 95th percentile loan fee (bps, per year) of stock $s$ on day $t$ (columns 4 to 6 ), After $r_{t}$ is a dummy variable that equals one from March 1,2011 onward, $t$ is a linear time trend, $\boldsymbol{X}_{\boldsymbol{s}, t}$ are control variables related to stock $s$ on day $t$, and $\alpha_{s}$ are stock fixed effects. We include the following variables in $\boldsymbol{X}_{\boldsymbol{s}, t}$ : i) the stock return over the last the 5 days, ii) the stock return over the last the 240 days, and iii) the standard deviation of daily stock returns computed using the last 15 days. Standard errors are clustered by stock and t-statistics are presented in parentheses. ***, $* *$, and * indicate significance at the $1 \%, 5 \%$, and $10 \%$ levels, respectively.

\begin{tabular}{ccccccc} 
& \multicolumn{3}{c}{ Loan fee 5th percentile } & \multicolumn{2}{c}{ Loan fee 95th percentile } \\
& $(1)$ & $(2)$ & $(3)$ & $(4)$ & $(5)$ & $(6)$ \\
\hline Trend & $1.18^{*}$ & $1.30^{* *}$ & $0.85^{*}$ & 3.54 & 3.59 & 2.80 \\
& $(1.90)$ & $(2.20)$ & $(1.93)$ & $(1.40)$ & $(1.40)$ & $(1.00)$ \\
Trend×After & $-1.51^{* * *}$ & $-1.54^{* * *}$ & $-1.31^{* * *}$ & $-4.18^{* *}$ & $-4.21^{* *}$ & $-3.58^{* *}$ \\
& $(-3.41)$ & $(-3.44)$ & $(-3.97)$ & $(-2.36)$ & $(-2.35)$ & $(-2.26)$ \\
Ret[-5] & & & 0.96 & & & 1.42 \\
& & & $(0.93)$ & & & $(0.51)$ \\
Ret[-240] & & & 0.29 & & & -3.47 \\
& & & $(0.51)$ & & & $(-0.93)$ \\
Volatility[-10] & & & 3.25 & & & 9.88 \\
& & & $(0.35)$ & & & $(0.29)$ \\
Constant & $142.29 * * *$ & $140.23^{* * *}$ & $138.85^{* * *}$ & $386.63^{* * *}$ & $385.97^{* * *}$ & $211.89^{* * *}$ \\
& $(5.69)$ & $(19.07)$ & $(6.40)$ & $(5.80)$ & $(10.55)$ & $(4.83)$ \\
Fixed effects & No & Stock & Stock & No & Stock & Stock \\
Observations & 1,163 & 1,163 & 1,163 & 1,163 & 1,163 & 1,163 \\
R2 & $0.66 \%$ & $73.56 \%$ & $73.66 \%$ & $0.81 \%$ & $52.31 \%$ & $52.60 \%$ \\
\hline \hline
\end{tabular}


Table 4: Benchmark effect on the loan fee level: Deal level regressions

This table presents the deal-level panel regression

$$
\mathrm{Fee}_{i, s, t, k}=\beta_{0}+\beta_{1} t+\beta_{2} t \times \text { After }_{t}+\boldsymbol{\beta}_{\mathbf{3}}^{\prime} \boldsymbol{X}_{\boldsymbol{s}, t}+\alpha_{s, k}+\varepsilon_{i, s, t, k}
$$

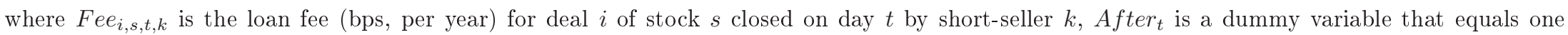
from March 1, 2011 onward, $t$ is a linear time trend, $\boldsymbol{X}_{\boldsymbol{s}, t}$ are control variables related to stock $s$ on day $t$. In columns 2 and 6 we include stock fixed-effects $\alpha_{s}$, and in columns 3, 4, 7, and 8, we include $\alpha_{s, k}$, investor-stock fixed-effects (a dummy for each pair stock-investor). We include the following variables in $\boldsymbol{X}_{s, t}$ : i) the stock return over the last the 5 days, ii) the stock return over the last the 240 days, and iii) the standard deviation of daily stock returns computed using the last 15 days. The regressions in columns $5,6,7$, and 8 are weighted by the total number of deals in each stock-day, so that each stock has the same weight on the estimates regardless their number of loan deals. Standard errors are clustered by stock and t-statistics are presented in parentheses. $* * *, * *$, and $*$ indicate significance at the $1 \%, 5 \%$, and $10 \%$ levels, respectively.

\begin{tabular}{ccccccccc} 
& \multicolumn{7}{c}{ Loan fee of the deal } \\
& $(1)$ & $(2)$ & $(3)$ & $(4)$ & $(5)$ & $(6)$ & $(7)$ & $(8)$ \\
\hline Trend & 2.22 & $2.59^{*}$ & 1.87 & 0.88 & 1.76 & 1.66 & 1.16 & 0.05 \\
& $(1.18)$ & $(1.83)$ & $(1.36)$ & $(0.46)$ & $(1.19)$ & $(1.54)$ & $(1.13)$ & $(0.03)$ \\
Trend $\times$ After & $-2.64^{* *}$ & $-2.78^{* *}$ & $-2.64^{* *}$ & $-1.85^{* * *}$ & $-2.73^{* *}$ & $-2.74^{* * *}$ & $-2.69^{* *}$ & $-1.86^{* * *}$ \\
& $(-2.18)$ & $(-2.68)$ & $(-2.14)$ & $(-3.85)$ & $(-2.58)$ & $(-3.05)$ & $(-2.44)$ & $(-3.82)$ \\
Constant & $243.60^{* * *}$ & $238.27^{* * *}$ & $250.33^{* * *}$ & $251.67^{* * *}$ & $249.09^{* * *}$ & $251.13^{* * *}$ & $260.12^{* * *}$ & $267.19^{* * *}$ \\
& $(4.14)$ & $(9.65)$ & $(8.29)$ & $(4.91)$ & $(4.95)$ & $(15.02)$ & $(12.26)$ & $(5.68)$ \\
Fixed effects & No & Stock & Stock-Id & Stock-Id & No & Stock & Stock-Id & Stock-Id \\
Controls & No & No & No & Yes & No & No & No & Yes \\
Weights & No & No & No & No & $\#$ deals & $\#$ deals & $\#$ deals & $\#$ deals \\
Observations & 51,411 & 51,411 & 51,411 & 51,411 & 51,411 & 51,411 & 51,411 & 51,411 \\
R2 & $0.52 \%$ & $58.60 \%$ & $73.89 \%$ & $74.48 \%$ & $3.75 \%$ & $60.59 \%$ & $76.53 \%$ & $76.74 \%$ \\
\hline \hline
\end{tabular}


Table 5: Benchmark effect on the loan fee level: Heterogeneous effects across stocks

This table presents the stock-day panel regression

$$
\begin{aligned}
\phi_{s, t} & =\beta_{0}+\beta_{1} t+\beta_{2} t \times \text { After }_{t} \\
& +\beta_{3} \text { High }_{s}+\beta_{4} t \times \text { High }_{s}+\beta_{5} t \times A f t e r_{t} \times H i g h_{s}+\boldsymbol{\beta}_{\mathbf{6}}^{\prime} \boldsymbol{X}_{\boldsymbol{s}, t}+\alpha_{s}+\varepsilon_{s, t}
\end{aligned}
$$

where $\phi_{s, t}$ can be the average loan fee (bps, per year) of stock $s$ on day $t$ (columns 1 to 3 ), the median loan fee (bps, per year) of stock $s$ on day $t$ (columns 4 to 6 ), the 5 th percentile loan fee in bps of stock $s$ on day $t$ (columns 7 to 9 ), and the 95th percentile loan fee (bps, per year) of stock $s$

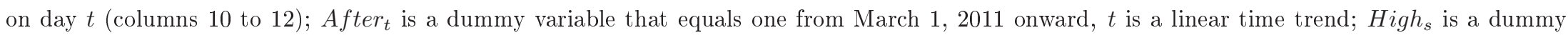
variable that equals one for the stocks with high loan fee volatility before the benchmark change; $\boldsymbol{X}_{\boldsymbol{s}, t}$ are control variables related to stock $s$ on day $t$; and $\alpha_{s}$ are stock fixed effects. We include the following variables in $\boldsymbol{X}_{\boldsymbol{s}, t}$ : i) the stock return over the last the 5 days, ii) the stock return over the last the 240 days, and iii) the standard deviation of daily stock returns computed using the last 15 days. Standard errors are clustered by stock and t-statistics are presented in parentheses. $* * *, * *$, and * indicate significance at the $1 \%, 5 \%$, and $10 \%$ levels, respectively.

\begin{tabular}{|c|c|c|c|c|c|c|c|c|c|c|c|c|}
\hline & \multicolumn{3}{|c|}{ Average loan fee } & \multicolumn{3}{|c|}{ Median loan fee } & \multicolumn{3}{|c|}{ Loan fee 5 th percentile } & \multicolumn{3}{|c|}{ Loan fee 95th percentile } \\
\hline & (1) & (2) & (3) & (4) & (5) & (6) & (7) & (8) & (9) & $(10)$ & (11) & (12) \\
\hline \multirow[t]{2}{*}{ Trend } & 0.29 & 0.27 & -0.67 & 0.21 & 0.19 & -0.76 & 0.33 & 0.32 & -0.13 & 0.78 & 0.74 & -0.21 \\
\hline & $(0.39)$ & $(0.35)$ & $(0.52)$ & $(0.26)$ & $(0.23)$ & $(-0.53)$ & $(1.12)$ & $(1.05)$ & $(-0.23)$ & $(0.43)$ & $(0.41)$ & $(-0.09)$ \\
\hline \multirow[t]{2}{*}{ Trend $\times$ After } & -0.46 & -0.47 & 0.18 & -0.55 & -0.56 & 0.19 & -0.70 & -0.70 & -0.44 & 0.20 & 0.19 & 0.98 \\
\hline & $(-0.94)$ & $(-0.94)$ & $(0.23)$ & $(-1.10)$ & $(-1.10)$ & $(0.20)$ & $(-1.58)$ & $(-1.57)$ & $(-0.91)$ & $(0.20)$ & $(0.28)$ & $(0.96)$ \\
\hline \multirow[t]{2}{*}{ Trend $\times$ High } & $2.77^{* *}$ & 2.99 & 3.02 & 1.84 & 2.08 & 2.06 & 1.70 & $1.96^{*}$ & $1.93^{*}$ & 5.59 & 5.71 & 5.69 \\
\hline & $(1.30)$ & $(1.41)$ & $(1.42)$ & $(0.89)$ & $(1.01)$ & $(1.00)$ & $(1.43)$ & $(1.74)$ & $(1.75)$ & $(1.13)$ & $(1.14)$ & $(1.11)$ \\
\hline \multirow[t]{2}{*}{ Trend $\times$ After $\times$ High } & $-4.52^{* *}$ & $-4.58^{* *}$ & $-4.64 * *$ & $-4.00^{* *}$ & $-4.06 * *$ & $-4.12^{* *}$ & $-1.63^{*}$ & $-1.68^{*}$ & $-1.72 *$ & $-8.78^{* * *}$ & $-8.84 * * *$ & $-8.89^{* *}$ \\
\hline & $(-2.49)$ & $(-2.49)$ & $(-2.44)$ & $(-2.09)$ & $(-2.10)$ & $(-2.05)$ & $(-1.96)$ & $(-2.00)$ & $(-2.06)$ & $(-2.80)$ & $(-2.78)$ & $(-2.68)$ \\
\hline \multirow[t]{2}{*}{ High } & 149.22 & & & 156.56 & & & 51.11 & & & $252.33^{*}$ & & \\
\hline & $(1.72)$ & & & $(1.62)$ & & & $(1.04)$ & & & $(2.02)$ & & \\
\hline \multirow[t]{2}{*}{ Constant } & $174.42^{* * *}$ & $247.46^{* * *}$ & $247.09^{* * *}$ & $166.58^{* * *}$ & $243.07^{* * *}$ & $229.24^{* * *}$ & $116.69^{* * *}$ & $140.25^{* * *}$ & $138.08^{* * *}$ & $260.34^{* * *}$ & $385.99^{* * *}$ & $369.53^{* * *}$ \\
\hline & $(4.79)$ & $(14.78)$ & $(7.47)$ & $(4.21)$ & $(12.81)$ & $(6.12)$ & $(4.84)$ & $(21.47)$ & $(6.44)$ & $(5.43)$ & $(10.56)$ & $(5.16)$ \\
\hline Fixed effects & No & Stock & Stock & No & Stock & Stock & No & Stock & Stock & No & Stock & Stock \\
\hline Controls & No & No & Yes & No & No & Yes & No & No & Yes & No & No & Yes \\
\hline Observations & 1,163 & 1,163 & 1,163 & 1,163 & 1,163 & 1,163 & 1,163 & 1,163 & 1,163 & 1,163 & 1,163 & 1,163 \\
\hline R2 & $11.36 \%$ & $83.25 \%$ & $83.49 \%$ & $9.60 \%$ & $82.01 \%$ & $82.40 \%$ & $7.32 \%$ & $73.67 \%$ & $73.79 \%$ & $13.27 \%$ & $54.63 \%$ & $53.93 \%$ \\
\hline
\end{tabular}


Table 6: Benchmark effect on loan volume

This table shows the estimates of stock-day panel regressions of $V_{s, t}$, the total volume in thousands of US\$ across all loan deals on stock $s$ in day $t$, and $\ln V_{s, t}$, the natural $\log$ of $V_{s, t}$. As before, we include as regressors After, a dummy variable that equals one from March 1, 2011 onward, $t$, a linear time trend, $\boldsymbol{X}_{\boldsymbol{s}, t}$, control variables related to stock $s$ on day $t$, and $\alpha_{s}$, stock fixed effects. Standard errors are clustered by stock and t-statistics are presented in parentheses. ${ }^{* * *}, * *$, and $*$ indicate significance at the $1 \%, 5 \%$, and $10 \%$ levels, respectively.

\begin{tabular}{ccccccc} 
& \multicolumn{2}{c}{ Total volume (in US\$ thousand) } & \multicolumn{3}{c}{$\log ($ total volume) } \\
& $(1)$ & $(2)$ & $(3)$ & $(4)$ & $(5)$ & $(6)$ \\
\hline Trend & $-187.90^{* *}$ & $-191.04^{* *}$ & $-172.45^{* *}$ & $-0.025^{* * *}$ & $-0.026^{* * *}$ & $-0.030^{* * *}$ \\
& $(-2.46)$ & $(-2.47)$ & $(-1.88)$ & $(-4.02)$ & $(-4.42)$ & $(-3.54)$ \\
Trend $\times$ After & $130.95^{* *}$ & $130.78^{* *}$ & $125.06^{* *}$ & $0.017^{* * *}$ & $0.017^{* * *}$ & $0.019^{* * *}$ \\
& $(2.61)$ & $(2.58)$ & $(2.06)$ & $(4.48)$ & $(4.41)$ & $(4.30)$ \\
Ret[-5] & & & -39.74 & & & 0.007 \\
& & & $(-0.66)$ & & & $(0.76)$ \\
Ret[-240] & & & -5.24 & & & 0.004 \\
& & & $(-0.17)$ & & & $(0.72)$ \\
Volatility[-10] & & & 678.04 & & & 0.063 \\
& & & $(0.48)$ & & & $(0.63)$ \\
Constant & $9,250^{* * *}$ & $9,315^{* * *}$ & $7,765^{* * *}$ & $8.381^{* * *}$ & $8.409^{* * *}$ & $8.315^{* * *}$ \\
& $(5.15)$ & $(11.04)$ & $(2.83)$ & $(37.63)$ & $(101.06)$ & $(33.92)$ \\
Fixed effects & No & Stock & Stock & No & Stock & Stock \\
Observations & 1,163 & 1,163 & 1,163 & 1,163 & 1,163 & 1,163 \\
R2 & $0.40 \%$ & $34.71 \%$ & $34.77 \%$ & $0.60 \%$ & $60.65 \%$ & $60.79 \%$ \\
\hline \hline
\end{tabular}


Table 7: Benchmark effect on lending activity concentration

This table shows the estimates of stock-day panel regressions of the number of different lenders of stock $s$ on day $t$ (columns 1 to 3 ), the concentration of lenders as measured by the Herfindahl-Hirschman index (HHI) of the fraction of deals closed by each lender for stock $s$ on day $t$ (columns 4 to 6), and the market share (in \%) of inefficient lenders for stock $s$ on day $t$ (columns 7 to 9). To compute the market share of inefficient lenders for stock $s$ on day $t$ we do as follows. We first classify all lenders with at least one loan deal in February 2011 as "efficient" or "inefficient". A lender is classified as inefficient if he charged an "expensive" loan fee in more than 50\% of the loan deals closed by him in February 2011 (the loan fee is defined as expensive if it is higher than the average loan fee for the stock on the day); otherwise, the lender is classified as efficient. We then compute for each stock-day in February and March 2011 the fraction of deals closed by all lenders classified as inefficient. As before, we include as regressors After a dummy variable that equals one from March 1, 2011 onward; $t$, is a linear time trend; $\boldsymbol{X}_{\boldsymbol{s}, t}$, control variables related to stock $s$ on day $t$; and $\alpha_{s}$, stock fixed effects. Standard errors are clustered by stock and t-statistics are presented in parentheses. ${ }^{* * *},{ }^{* *}$, and ${ }^{*}$ indicate significance at the $1 \%$, $5 \%$, and $10 \%$ levels, respectively.

\begin{tabular}{cccccccccc} 
& \multicolumn{3}{c}{ Log(number of lenders) } & \multicolumn{3}{c}{ Lenders HHI } & \multicolumn{3}{c}{ Mkt. share of ineff. lenders } \\
& $(1)$ & $(2)$ & $(3)$ & $(4)$ & $(5)$ & $(6)$ & $(7)$ & $(8)$ & $(9)$ \\
\hline Trend & $-0.01^{* *}$ & $-0.01^{* *}$ & $-0.01^{* * *}$ & $0.16^{* * *}$ & $0.16^{* * *}$ & $0.19^{* * *}$ & 0.08 & 0.08 & 0.13 \\
& $(-2.57)$ & $(-2.53)$ & $(-3.09)$ & $(4.26)$ & $(4.21)$ & $(4.60)$ & $(1.01)$ & $(0.96)$ & $(1.15)$ \\
Trend $\times$ After & 0.003 & 0.004 & $0.005^{*}$ & $-0.10^{* * *}$ & $-0.10^{* * *}$ & $-0.11^{* * *}$ & $-0.21^{* * *}$ & $-0.21^{* * *}$ & $-0.24^{* * *}$ \\
& $(1.42)$ & $(1.40)$ & $(1.93)$ & $(-2.95)$ & $(-2.91)$ & $(-3.42)$ & $(-2.87)$ & $(-2.84)$ & $(-2.80)$ \\
Ret[-5] & & & 0.007 & & & -0.04 & & & -0.12 \\
& & & $(1.67)$ & & & $(-0.94)$ & & & $(-0.74)$ \\
Ret[-240] & & & 0.001 & & & 0.05 & & & -0.01 \\
& & & $(0.32)$ & & & $(1.12)$ & & & $(-0.08)$ \\
Volatility[-10] & & & -0.02 & & & 1.14 & & & -0.04 \\
& & & $(0.30)$ & & & $(1.40)$ & & & $(-0.02)$ \\
Constant & $3.01^{* * *}$ & $3.01^{* * *}$ & $22.58^{* * *}$ & $8.09^{* * *}$ & $8.09^{* * *}$ & $5.35^{* * *}$ & $70.76^{* * *}$ & $70.85^{* * *}$ & $70.20^{* * *}$ \\
& $(25.59)$ & $(75.34)$ & $(22.58)$ & $(7.68)$ & $(20.42)$ & $(2.87)$ & $(18.17)$ & $(54.05)$ & $(15.43)$ \\
Fixed effects & No & Stock & Stock & No & Stock & Stock & No & Stock & Stock \\
Observations & 1,163 & 1,163 & 1,163 & 1,163 & 1,163 & 1,163 & 1,163 & 1,163 & 1,163 \\
R2 & $0.40 \%$ & $65.89 \%$ & $66.11 \%$ & $0.55 \%$ & $47.58 \%$ & $47.81 \%$ & $1.92 \%$ & $54.36 \%$ & $54.41 \%$ \\
\hline \hline
\end{tabular}


Table 8: Benchmark effect on lenders' total revenue

This table shows the estimates of stock-day panel regressions of lenders' total revenue in thousands of US $\$$ for each stock-day and its natural log as dependent variables. As before, we include as regressors $A f t e r$, a dummy variable that equals one from March 1, 2011 onward, $t$, a linear time trend, $\boldsymbol{X}_{\boldsymbol{s}, \boldsymbol{t}}$, control variables related to stock $s$ on day $t$, and $\alpha_{s}$, stock fixed effects. Standard errors are clustered by stock and t-statistics are presented in parentheses. $* * *, * *$, and $*$ indicate significance at the $1 \%, 5 \%$, and $10 \%$ levels, respectively.

\begin{tabular}{|c|c|c|c|c|c|c|}
\hline & \multicolumn{3}{|c|}{ Lenders' total revenue (in US\$ thousand) } & \multicolumn{3}{|c|}{ Log(lenders' total revenue) } \\
\hline & (1) & (2) & $(3)$ & $(4)$ & $(5)$ & (6) \\
\hline \multirow[t]{2}{*}{ Trend } & $-191.23^{* *}$ & $-196.34^{* *}$ & -124.09 & $-0.020^{* * *}$ & $-0.021^{* * *}$ & $-0.024^{* * *}$ \\
\hline & $(-2.23)$ & $(-2.26)$ & $(-0.85)$ & $(-3.19)$ & $(-3.36)$ & $(-2.76)$ \\
\hline \multirow[t]{2}{*}{ Trend $\times$ After } & 80.02 & 79.24 & 51.03 & 0.007 & 0.006 & $0.008^{*}$ \\
\hline & $(1.35)$ & $(1.32)$ & $(0.79)$ & $(1.47)$ & $(1.43)$ & $(1.69)$ \\
\hline \multirow[t]{2}{*}{$\operatorname{Ret}[-5]$} & & & -166.57 & & & 0.008 \\
\hline & & & $(-0.62)$ & & & $(0.70)$ \\
\hline \multirow{2}{*}{$\operatorname{Ret}[-240]$} & & & -214.28 & & & 0.005 \\
\hline & & & $(-1.05)$ & & & $(0.71)$ \\
\hline \multirow[t]{2}{*}{ Volatility[-10] } & & & -402.37 & & & -0.015 \\
\hline & & & $(-0.16)$ & & & $(-0.11)$ \\
\hline \multirow[t]{2}{*}{ Constant } & $15,850^{* * *}$ & $15,963^{* * *}$ & $16,732^{* *}$ & $8.554^{* * *}$ & $8.574^{* * *}$ & $8.630^{* * *}$ \\
\hline & (3.89) & $(9.29)$ & $(2.44)$ & $(32.79)$ & $(91.87)$ & $(24.95)$ \\
\hline Fixed effects & No & Stock & Stock & No & Stock & Stock \\
\hline Observations & 1,163 & 1,163 & 1,163 & 1,163 & 1,163 & 1,163 \\
\hline $\mathrm{R} 2$ & $0.17 \%$ & $42.44 \%$ & $42.81 \%$ & $0.59 \%$ & $71.87 \%$ & $71.97 \%$ \\
\hline
\end{tabular}


Table 9: Price efficiency measures around benchmark change

This table presents four measures of stock price inefficiency computed before and after the change in the loan fee benchmark. D1 and D2 are based on the following stock-week regressions

$$
R_{s, w}=\beta_{0}+\beta_{1} R_{m, w}+\sum_{i=1}^{4} \delta_{i} R_{m, w-i}+\epsilon_{s, w}
$$

where $R_{s, w}$ is the stock return for stock $s$ in week $w$ and $R_{s, w}$ is the market return in week $w$. D1 is equal to $1-R_{R}^{2} / R_{U}^{2}$, where $R_{U}^{2}$ is the R-squared from the regression above (unrestricted regression), and $R_{R}^{2}$ is the R-squared from the regression above restricting $\delta_{i}$ to be zero (restricted regression). D2 is equal to the ratio of t-statistics $\sum_{i=1}^{4} t\left(\delta_{i}\right) /\left[t\left(\beta_{1}\right)+\sum_{i=1}^{4} t\left(\delta_{i}\right)\right]$, where $t()$ denotes the t-statistic of the coefficient. D3 and D4 are based on a similar regression where the stock market return is replace by $R_{m, w}^{-}$, which equals the market return when it is negative and zero otherwise. D3 is equal to $1-\widetilde{R}_{R}^{2} / \widetilde{R}_{U}^{2}$, where $\widetilde{R}$ is the R-squared from the regressions using $R_{m, w}^{-}$, and D4 is the ratio of t-statistics $\sum_{i=1}^{4} t\left(\delta_{i}^{-}\right) /\left[t\left(\beta_{1}^{-}\right)+\sum_{i=1}^{4} t\left(\delta_{i}^{-}\right)\right]$. We use 3-, 6-, and 12-month windows to estimate the price efficiency measure. Test of differences are nonparametric Kruskal-Wallis tests, and their corresponding p-values are in parentheses.

\begin{tabular}{ccccc} 
& D1 & D2 & D3 & D4 \\
\hline \multicolumn{5}{c}{ 3-month window } \\
\hline Before (B) & 0.462 & 0.664 & 0.550 & 0.667 \\
After (A) & 0.426 & 0.627 & 0.464 & 0.636 \\
$A-B$ & -0.036 & -0.037 & -0.086 & -0.031 \\
p-value & $(0.554)$ & $(0.375)$ & $(0.169)$ & $(0.287)$ \\
\hline \multicolumn{5}{c}{6 -month window } \\
\hline Before (B) & 0.356 & 0.538 & 0.456 & 0.637 \\
After (A) & 0.209 & 0.460 & 0.295 & 0.507 \\
$A-B$ & -0.147 & -0.078 & -0.161 & -0.130 \\
p-value & $(0.005)$ & $(0.028)$ & $(0.007)$ & $(0.001)$ \\
\hline \multicolumn{5}{c}{12 -month window } \\
\hline Before (B) & 0.277 & 0.493 & 0.382 & 0.572 \\
After (A) & 0.151 & 0.389 & 0.212 & 0.434 \\
$A$ - $B$ & -0.126 & -0.104 & -0.170 & -0.138 \\
p-value & $(0.006)$ & $(0.014)$ & $(0.001)$ & $(0.001)$ \\
\hline \hline
\end{tabular}


Table 10: Benchmark effect on the loan fee level: Day fixed-effects

This table presents the stock-day panel regression

$$
\phi_{s, t}=\beta_{0}+\gamma_{t}+\boldsymbol{\beta}_{\mathbf{3}}^{\prime} \boldsymbol{X}_{\boldsymbol{s}, \boldsymbol{t}}+\alpha_{s}+\varepsilon_{s, t}
$$

where $\phi_{s, t}$ is either the average loan fee (bps, per year) of stock $s$ on day $t$ (columns 1 an 2) or the median loan fee (bps, per year) of stock $s$ on day $t$ (columns 3 and 4 ), $\gamma_{t}$ are day fixed-effects (on the table, "day $-n$ " refers to $n$ days before the benchmark change and "day $+n$ " refers to $n$ days after the benchmark change), $\boldsymbol{X}_{s, t}$ are control variables related to stock $s$ on day $t$, and $\alpha_{s}$ are stock fixed effects. We include the following variables in $\boldsymbol{X}_{\boldsymbol{s}, t}$ : i) the stock return over the last the 5 days, ii) the stock return over the last the 240 days, and iii) the standard deviation of daily stock returns computed using the last 15 days. Standard errors are clustered by stock and ${ }^{* * *}, * *$, and $*$ indicate significance at the $1 \%, 5 \%$, and $10 \%$ levels, respectively.

Average loan fee Median loan fee

\begin{tabular}{|c|c|c|c|c|}
\hline & (1) & (2) & (3) & (4) \\
\hline day -19 & -24.47 & -13.72 & $\begin{array}{l}-29.07 \\
\end{array}$ & $\begin{array}{l}-16.62 \\
\end{array}$ \\
\hline day -18 & -38.79 & -26.21 & -24.02 & -10.06 \\
\hline day -17 & -26.47 & -19.66 & -20.55 & -15.15 \\
\hline day -16 & -20.97 & -15.08 & -6.63 & -2.35 \\
\hline day -15 & -14.60 & -10.22 & -16.70 & -15.57 \\
\hline day -14 & -28.49 & -21.81 & -38.28 & -34.19 \\
\hline day -13 & -8.80 & 0.13 & 7.98 & 15.91 \\
\hline day -12 & 4.32 & 10.48 & -1.22 & 2.01 \\
\hline day -11 & -14.35 & -11.68 & -2.72 & -3.45 \\
\hline day -10 & -5.59 & -2.73 & 1.28 & 1.01 \\
\hline day -9 & -1.76 & 0.85 & -5.47 & -6.25 \\
\hline day -8 & -0.05 & 1.35 & 1.05 & 0.81 \\
\hline day -7 & -2.72 & -3.98 & -0.85 & -3.76 \\
\hline day -6 & 24.61 & 24.54 & 9.70 & 9.58 \\
\hline day -5 & 29.00 & 38.40 & 1.38 & 10.34 \\
\hline day -4 & 14.28 & 7.74 & 7.83 & -2.32 \\
\hline day -3 & 4.09 & -3.59 & 8.68 & -1.79 \\
\hline day -2 & -5.37 & -9.98 & -7.78 & -15.07 \\
\hline day -1 & 11.88 & 10.80 & 17.25 & 15.53 \\
\hline day +1 & -9.17 & -9.42 & -8.30 & -10.78 \\
\hline day +2 & $-23.40 * * *$ & $-22.53^{* *}$ & $-23.93^{* *}$ & $-24.06^{* *}$ \\
\hline day +3 & $-41.15^{* *}$ & $-39.85^{* * *}$ & $-48.75^{* * *}$ & $-48.55 * * *$ \\
\hline day +4 & -15.28 & -18.23 & -15.76 & -18.83 \\
\hline day +5 & -15.69 & -15.92 & $-28.60^{* *}$ & $-28.84^{* *}$ \\
\hline day +6 & $-35.91^{* *}$ & $-36.45^{* *}$ & $-33.13^{* *}$ & $-33.84^{* *}$ \\
\hline day +7 & $-56.58 * * *$ & $-53.31 * * *$ & $-51.72^{* * *}$ & $-47.12^{* *}$ \\
\hline day +8 & $-59.36^{* *}$ & $-53.70 * *$ & $-63.42^{* * *}$ & $-55.01 * *$ \\
\hline day +9 & $-56.10^{* *}$ & $-56.28 * *$ & $-69.07^{* *}$ & $-70.21^{* *}$ \\
\hline day +10 & $-42.62^{*}$ & -39.55 & $-58.02^{* *}$ & $-54.92^{* *}$ \\
\hline
\end{tabular}

(continuous on the next page...) 
(...continued from previous page)

Average loan fee Median loan fee

\begin{tabular}{ccccc} 
& $(1)$ & $(2)$ & $(3)$ & $(4)$ \\
\hline day +11 & -50.46 & -37.78 & $-66.95^{* *}$ & $-52.98^{*}$ \\
day +12 & $-54.64^{*}$ & $-52.82^{*}$ & -50.58 & -49.12 \\
day +13 & $-76.02^{* *}$ & $-74.35^{* *}$ & $-78.85^{* *}$ & $-77.36^{* *}$ \\
day +14 & $-89.54^{* *}$ & $-79.16^{* *}$ & $-87.33^{* *}$ & $-75.50^{* *}$ \\
day +15 & $-69.20^{*}$ & $-65.62^{*}$ & $-79.48^{* *}$ & $-75.25^{* *}$ \\
day +16 & $-76.94^{*}$ & $-72.50^{*}$ & $-74.16^{*}$ & -67.51 \\
day +17 & -60.59 & -56.30 & $-82.88^{* *}$ & $-77.34^{* *}$ \\
day +18 & -59.98 & -47.59 & $-76.96^{* *}$ & $-61.61^{*}$ \\
day +19 & -63.70 & -59.68 & -59.08 & -50.99 \\
Constant $($ day 0$)$ & $269.78^{* * *}$ & $270.31^{* * *}$ & $259.55^{* * *}$ & $246.97^{* * *}$ \\
Controls & No & Yes & No & Yes \\
Fixed effects & No & Stock & No & Stock \\
Observations & 1,163 & 1,163 & 1,163 & 1,163 \\
R2 & $1.69 \%$ & $82.83 \%$ & $1.64 \%$ & $81.58 \%$ \\
\hline \hline
\end{tabular}


Table 11: Benchmark effect on the loan fee level: Other intervals

This table presents the stock-day panel regression

$$
\phi_{s, t}=\beta_{0}+\beta_{1} t+\beta_{2} t \times \text { After }_{t}+\boldsymbol{\beta}_{\mathbf{3}}^{\prime} \boldsymbol{X}_{\boldsymbol{s}, t}+\alpha_{s}+\varepsilon_{s, t}
$$

where $\phi_{s, t}$ can be the average loan fee (bps, per year) of stock $s$ on day $t$ (columns 1 and 5 ), the median loan fee (bps, per year) of stock $s$ on day $t$ (columns 2 and 6 ), the 5 th percentile loan fee (bps, per year) of stock $s$ on day $t$ (columns 3 and 7 ), and the 95 th percentile loan fee (bps, per year) of

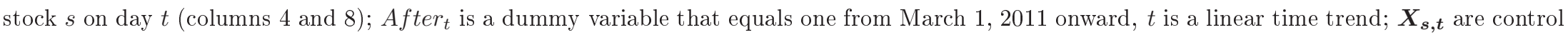
variables related to stock $s$ on day $t$; and $\alpha_{s}$ are stock fixed effects. We include the following variables in $\boldsymbol{X}_{s, t}$ : i) the stock return over the last the 5 days, ii) the stock return over the last the 240 days, and iii) the standard deviation of daily stock returns computed using the last 15 days. We use all loan deals from January 2011 to April 2011 (columns 1 to 4) or all loan deals from November 2010 to June 2011 (columns 5 to 8 ). Standard errors are clustered by stock and t-statistics are presented in parentheses. $* * *, * *$, and $*$ indicate significance at the $1 \%, 5 \%$, and $10 \%$ levels, respectively.

\begin{tabular}{ccccccccc} 
& \multicolumn{3}{c}{ Interval: Jan 2011-April 2011} & \multicolumn{3}{c}{ Interval: Nov 2010 - Jun 2010 } \\
& Mean & Median & 5th pct & 95 th pct & Mean & Median & 5th pct & 95 th pct \\
& $(1)$ & $(2)$ & $(3)$ & $(4)$ & $(5)$ & $(6)$ & $(7)$ & $(8)$ \\
\hline Trend & -0.79 & -0.97 & 0.04 & -0.88 & 1.80 & 2.16 & $1.54^{*}$ & 1.03 \\
& $(-0.89)$ & $(-1.23)$ & $(0.11)$ & $(-0.53)$ & $(1.58)$ & $(1.72)$ & $(2.08)$ & $(0.86)$ \\
Trend $\times$ After & $-0.91^{*}$ & -1.00 & $-0.61^{* * *}$ & $-0.97^{*}$ & $-1.15^{*}$ & $-1.37^{*}$ & $-0.65^{* * *}$ & -1.01 \\
& $(-1.93)$ & $(-1.59)$ & $(-2.93)$ & $(-1.98)$ & $(-1.83)$ & $(-1.84)$ & $(-3.39)$ & $(-1.26)$ \\
Ret[-5] & 1.73 & 1.42 & 1.21 & 3.32 & 2.10 & 1.62 & 1.15 & 3.76 \\
& $(1.05)$ & $(0.88)$ & $(1.04)$ & $(1.32)$ & $(1.09)$ & $(0.86)$ & $(0.87)$ & $(1.55)$ \\
Ret[-240] & 0.98 & 1.12 & 0.31 & 0.96 & -0.92 & -0.82 & -1.33 & -0.61 \\
& $(0.60)$ & $(0.74)$ & $(0.32)$ & $(0.37)$ & $(-0.46)$ & $(-0.40)$ & $(-1.02)$ & $(-0.27)$ \\
Volatility[-10] & -12.23 & -9.07 & 1.04 & -14.65 & -25.17 & -28.19 & -2.35 & -25.29 \\
& $(-0.68)$ & $(-0.62)$ & $(0.09)$ & $(-0.34)$ & $(-1.05)$ & $(-1.12)$ & $(-0.11)$ & $(-0.80)$ \\
Constant & $319.45^{* * *}$ & $305.85^{* * *}$ & $151.63^{* * *}$ & $507.04^{* * *}$ & $236.80^{* * *}$ & $209.30^{* * *}$ & $80.42^{*}$ & $465.17^{* * *}$ \\
& $(6.56)$ & $(6.02)$ & $(6.99)$ & $(6.33)$ & $(4.43)$ & $(4.43)$ & $(1.79)$ & $(6.76)$ \\
Fixed effects & Stock & Stock & Stock & Stock & Stock & Stock & Stock & Stock \\
Observations & 1,326 & 1,326 & 1,326 & 1,326 & 2,176 & 2,176 & 2,176 & 2,176 \\
R2 & $68.88 \%$ & $68.26 \%$ & $58.76 \%$ & $43.70 \%$ & $52.34 \%$ & $52.15 \%$ & $40.05 \%$ & $38.33 \%$ \\
\hline \hline
\end{tabular}


Table 12: Benchmark effect on the loan fee level: The 2014 benchmark change

This table presents the stock-day panel regression

$$
\phi_{s, t}=\beta_{0}+\beta_{1} t+\beta_{2} t \times \text { After }_{t}+\boldsymbol{\beta}_{\mathbf{3}}^{\prime} \boldsymbol{X}_{\boldsymbol{s}, t}+\alpha_{s}+\varepsilon_{s, t}
$$

where $\phi_{s, t}$ is either the average loan fee (bps, per year) of stock $s$ on day $t$ (columns 1 to 3 ) or the median loan fee (bps, per year) of stock $s$ on day $t$ (columns 4 to 6), After $t_{t}$ is a dummy variable that equals one from February 17, 2014 onward (the date of the 2014 benchmark change), $t$ is a linear time trend, $\boldsymbol{X}_{\boldsymbol{s}, \boldsymbol{t}}$ are control variables related to stock $s$ on day $t$, and $\alpha_{s}$ are stock fixed effects. We include the following variables in $\boldsymbol{X}_{s, t}:$ i) the stock return over the last the 5 days, ii) the stock return over the last the 240 days, and iii) the standard deviation of daily stock returns computed using the last 15 days. We use all loan deals from January 17, 2014 to March 17, 2014 (20 days before and 20 days after the benchmark change occurred on February 17, 2014). Standard errors are clustered by stock and t-statistics are presented in parentheses. ***, **, and * indicate significance at the $1 \%, 5 \%$, and $10 \%$ levels, respectively.

\begin{tabular}{ccccccc} 
& \multicolumn{3}{c}{ Average loan fee } & \multicolumn{3}{c}{ Median loan fee } \\
& $(1)$ & $(2)$ & $(3)$ & $(4)$ & $(5)$ & $(6)$ \\
\hline Trend & -0.85 & -0.85 & -0.67 & -0.69 & -0.69 & -0.56 \\
& $(-0.24)$ & $(-0.24)$ & $(-0.20)$ & $(-0.19)$ & $(-0.19)$ & $(-0.16)$ \\
Trend×After & -0.30 & -0.30 & -0.90 & -0.18 & -0.18 & -0.74 \\
& $(-0.16)$ & $(-0.16)$ & $(-0.53)$ & $(-0.10)$ & $(-0.09)$ & $(-0.43)$ \\
Ret[-5] & & & 5.79 & & & 5.57 \\
& & & $(2.92)$ & & & $(2.60)$ \\
Ret[-240] & & & -7.17 & & & -6.76 \\
& & & $-2.33)$ & & & $-2.10)$ \\
Volatility[-10] & & & -26.51 & & & -23.28 \\
& & & $-1.45)$ & & & $(-1.17)$ \\
Constant & $462.63^{* * *}$ & $462.63^{* * *}$ & $456.10^{* * *}$ & $443.30^{* * *}$ & $443.30 * * *$ & $434.37^{* * *}$ \\
Fixed effects & $(4.79)$ & $(8.65)$ & $(8.27)$ & $(4.69)$ & $(8.13)$ & $(8.20)$ \\
Observations & No & Stock & Stock & No & Stock & Stock \\
R2 & $0.04 \%$ & 2,240 & 2,240 & 2,240 & 2,240 & 2,240 \\
\hline \hline
\end{tabular}

